\title{
EL PROBLEMA DE LOS ESTADOS MEDITERRÁNEOS O SIN LITORAL EN EL DERECHO INTERNACIONAL MARÍTIMO. UN ESTUDIO DE CASO: EL DIFERENDO BOLIVIA-PERÚ-CHILE
}

\author{
Juan Carlos VELÁZQUEZ ELIZARRARÁS*
}

RESUMEN: Es un hecho contundente que los Estados modernos le dan un tratamiento distinto y una prioridad singular a la disposición de litorales, la libertad de tránsito y el usufructo de los recursos marítimos adyacentes, en tanto que la ordenación legal y reglamentaria de los mares y océanos se ha complicado, pues han surgido nuevas figuras jurídicas de inexplorada complejidad como la zona contigua, la zona económica exclusiva, la plataforma continental y la zona de fondos marinos y oceánicos. En este escenario jurídico-político, si bien el enclaustramiento impuesto por Chile a Bolivia es en esencia un asunto bilateral, no le compete exclusivamente a los dos países, sino al equilibrio y al proceso de integración de la región, históricamente ineluctable.

ABSTRACT: It is a fact that modern States embrace coastal law, freedom of transit and the usufruct of adjacent maritime resources as a priority due to the emergence of a more complex system of law regarding the seas and oceans, as new and controversial figures have appeared such as the contiguous zone, the exclusive economic zone, the continental shelf and the seabed. Under these legal and political circumstances, while the restrictions imposed by Chile to Bolivia appeared to be in essence a bilateral issue, they are not exclusively an issue between these two-countries, but rather it is an issue of regional stability and integration.

RÉSUMÉ: C'est un fait que les Etats modernes traitent différemment et avec une priorité variable la disposition des littoraux, la liberté du transit et l'usufruit des ressources maritimes adjacentes, d'autant plus les normes légales et réglementaires concernant les mers et océans se sont compliquées car de nouvelles figures juridiques complexes telles que la zone contiguë, la zone économique exclusive, la plate-forme continentale et la zone des fonds marins océaniques sont apparues. Dans ce scénario juridique politique, si l'enfermement imposé par le Chili à la Bolivie est une affaire bilatérale en essence, ces deux pays ne sont pour autant pas les seuls compétents, mais la compétence se trouve dans l'équilibre et le processus d'intégration de la région, processus historiquement inéluctable.

* Profesor en la Facultad de Ciencias Políticas y Sociales, y profesor en el posgrado de derecho de la UNAM y de la Universidad Anáhuac del Sur. Doctor en ciencias políticas y sociales por la UNAM. Investigador nacional, nivel I, del SNI. El autor agradece sobremanera al gobierno del presidente de Bolivia, Evo Morales Aima, la información oficial actualizada que se sirvió facilitarle directamente para profundizar la presente investigación, misma que será próximamente convalidada en el propio territorio boliviano por invitación del actual gobierno constitucional de ese país hermano. 


\begin{abstract}
SUMARIO: I. Introducción. II. Antecedentes histórico-diplomáticos del diferendo territorial. III. Tratados, declaraciones y propuestas de solución, desde el fin de la Guerra del Pacífico hasta 1962. IV. El desarrollo de los hechos y las negociaciones relevantes en el periodo de 1975 a 2006. V. Balance general de los costos de la mediterraneidad de Bolivia. VI. El diferendo por la mediterraneidad de Bolivia en el marco de la Convención de las Naciones Unidas sobre Derecho del Mar.

VII. A manera de reflexión final. VIII. Bibliografía.
\end{abstract}

\title{
I. INTRODUCCIÓN
}

El problema de los Estados mediterráneos o sin litoral, sea cual fuere el origen de esa situación que les impide tener una salida natural al mar o poseer fronteras marítimas definidas, representa sin duda uno de los grandes temas actuales de las relaciones jurídicas internacionales y de la geopolítica de los océanos, que se inscribe en el núcleo duro del nuevo derecho del mar. Tradicionalmente, el derecho internacional clásico consideró como una única división de los espacios marinos, la existente entre una zona de soberanía del Estado ribereño y la alta mar. Sin embargo, con los avances tecnológicos, se incrementan y diversifican los usos y aprovechamiento del medio marino, y dichos espacios se llegan a considerar como zonas de gran potencialidad para el desarrollo económico de los países y no únicamente como áreas estratégicas ya sean militares o territoriales. Por eso los Estados modernos le dan un tratamiento distinto y una prioridad angular a la disposición de litorales, la libertad de tránsito y el usufructo de los recursos marítimos adyacentes.

La ordenación legal y reglamentaria de los mares y océanos se ha complicado, pues han surgido nuevas figuras jurídicas de inexplorada complejidad como la zona contigua, la zona económica exclusiva, la plataforma continental y la zona de fondos marinos y oceánicos. Recordemos que en un principio el derecho internacional del mar tuvo un carácter eminentemente consuetudinario y es sólo hasta 1958 cuando se convoca la Conferencia Internacional de Naciones Unidas sobre el Derecho del Mar, en la que se adoptan cuatro convenciones relativas al mar territorial, plataforma continental, alta mar, y la pesca y conservación de los recursos vivos en el mare nostrum. Posteriormente, en los trabajos de la III Confemar se introducen novedosos temas de enorme importancia como: los 
regímenes de islas, Estados archipielágicos, estrechos utilizados para la navegación internacional, zona económica exclusiva, derecho de acceso al mar y desde el mar de los Estados sin litoral y libertad de tránsito, Tribunal Internacional del Derecho del Mar, solución de controversias, y la empresa, entre otros rubros que son objeto de estudio de las ciencias jurídicas, políticas y sociales en este siglo XXI. ${ }^{1}$

Es cierto que estas convenciones se dan años después del inicio del conflicto que se va a abordar en el presente apartado capitular, el diferendo trinacional que origina la mediterraneidad de Bolivia, pero sin duda pueden ayudar a resolverlo. En estos días hay estudios, libros y artículos que continúan hablando del caso porque aún no se tiene una solución definitiva (para Bolivia), y se buscan soluciones viables bajo condiciones más propicias o por lo menos en la literatura y en las negociaciones diplomáticas y parlamentarias se manejan argumentos o se explican razones que tal vez en el contexto y tiempo en el que se dio el diferendo no se comprendían.

\section{ANTECEDENTES HISTÓRICO-DIPLOMÁTICOS DEL DIFERENDO TERRITORIAL}

\section{Antecedentes histórico-diplomáticos hasta la etapa previa a la Guerra del Pacífico}

Comenzaremos afirmando que Bolivia tiene títulos históricos sobre el litoral del Pacífico. Los derechos del país sobre territorios ubicados en las costas del Océano Pacífico se remontan a la época de la colonia española y su legitimidad está fuera de toda duda. Sin embargo, la insistencia de algunos historiadores chilenos en pretender demostrar lo contrario obliga a recordar algunos antecedentes histórico-diplomáticos.

El virreinato del Perú, entidad político-administrativa establecida por España en 1542, durante el periodo colonial incluyó los actuales territorios de Colombia, Ecuador, Bolivia y Perú, así como los de Chile y Argentina. Diversos estudios históricos testimonian que la Audiencia de Charcas, que fue la base administrativa sobre la cual se conformó poste-

1 Consúltese el trabajo de la Comisión Andina de Juristas, Impunidad y derecho penal internacional: Un estudio empírico dogmático sobre Colombia, Bolivia, Perú, Chile y Argentina, Colombia, 1997. 
riormente la República de Bolivia, limitaba con las costas del Pacífico. La Audiencia de Charcas abarcaba desde el río Loa en el norte (al norte de Tocopilla y al sur de Iquique, entonces territorio peruano) a $\operatorname{los} 21^{\circ} \mathrm{y}$ el río Salado en el sur (al sur de Taltal y al norte del valle de Copiapó) entre los grados 26 y 27. Las leyes IX y XII de la Recopilación de Indias establecen claramente esa jurisdicción de lo que a partir de 1825 fue el Departamento Boliviano de Potosí. El 18 de abril de 1548, el pacificador La Gasca, que definió los límites entre el Virreinato del Perú (Audiencia de Charcas en esa región) y la capitanía de Chile, estableció el paralelo 25 como la demarcación más al norte de Chile. Este mismo criterio fue expresado por don Pedro de Valdivia, conquistador de Chile en su carta al emperador Carlos V de 15 de octubre de 1550, en la que menciona textualmente el paralelo 25 como el límite más al norte de su jurisdicción. Queda claro que Chile nunca poseyó territorios más al norte del valle de Copiapó y que esa realidad fue sistemáticamente reconocida en todos los mapas que se publicaron en el mundo hasta 1880. Sobre esa base la soberanía boliviana era indiscutible cuando menos hasta el Paposo en el paralelo $25 .^{2}$

Desde 1776, la Audiencia de Charcas, que dependía del virreinato del Perú, pasó a formar parte del Virreinato del Río de La Plata. Charcas se desprendió de su antigua jurisdicción y el nuevo virreinato se creó con las gobernaciones de Paraguay y Tucumán, la Audiencia de Charcas y la Provincia de Cuyo, o sea, con lo que hoy son Bolivia, la Argentina, Paraguay, la Banda Oriental y el estado brasilero de Río Grande. La Audiencia de Charcas constaba de cuatro intendencias: La Paz, Santa Cruz, Potosí y Charcas. A su vez, la Intendencia de Potosí estaba dividida en seis partidos: Porco, Chayanta, Atacama, Lípez, Chichas y Tarija. Consecuentemente, el litoral sobre el Océano Pacífico o territorio de Atacama formaba parte de la Intendencia de Potosí. Atacama tenía por límite contiguo a Chile el río Salado, junto al Paposo a los $25^{\circ} 31^{\prime} 36^{\prime \prime}$ de latitud sur.

En 1825, Bolivia nació a la vida independiente con un territorio que incluía 400 kilómetros de costa sobre el Océano Pacífico. Después de la Guerra de Independencia, al ser establecido el territorio de los nuevos Estados americanos sobre la base del principio uti possidetis juris de 1810, base del derecho territorial de las flamantes repúblicas, la Repúbli-

2 Véase también Guzmán Galarza, Mario, Historia general de la América Latina, México, El Caballito, 1978. 
ca de Bolivia comprendía la antigua jurisdicción de la Audiencia de Charcas. En 1826, el mariscal Antonio José de Sucre, por entonces presidente de Bolivia, clarificó la división política del país. Las intendencias fueron convertidas en departamentos. Bolivia quedó dividida en cinco departamentos: Chuquisaca, La Paz, Cochabamba, Santa Cruz y Potosí. Los departamentos fueron divididos en provincias y éstas en cantones. Atacama era una de las provincias dependientes de la prefectura de Potosí, su capital era San Pedro de Atacama. ${ }^{3}$

En 1837, se creó el Departamento del Litoral. Políticamente, el Litoral se dividía en dos provincias: La Mar, cuya capital era Cobija, y Atacama, cuya capital era San Pedro de Atacama. La población del Litoral tenía, al nacer la República, alrededor de 3,700 habitantes; en 1885, 5,500 y en 1879 alrededor de 15,000. La superficie del Departamento del Litoral era de aproximadamente $120,000 \mathrm{~km} 2$. Dos ríos marcaban sus límites, al norte el Loa (con el Perú) y al sur el Salado (con Chile). En la costa boliviana: los puertos de Antofagasta, Cobija y Tocopilla, las bahías de Mejillones, Algodonales y Herradura y las caletas de Gatico, Guanillos, Michilla, Tames, Gualaguala, Cobre y Paquica. También se habían desarrollado poblados interiores como Calama y San Pedro de Atacama.

El estatus territorial de Bolivia nunca fue observado por la República de Chile, pues sus Constituciones políticas de 1822, 1823 y 1833 reconocieron que el límite norte de Chile era el desierto de Atacama. Lo propio ocurrió en el primer instrumento bilateral suscrito entre ambas naciones: el Tratado de Amistad, Comercio y Navegación, aprobado por el Congreso chileno entre 1833 y 1834. La creciente importancia del salitre, unida al hecho de que Bolivia contaba con escasa población en la provincia de Atacama y muy reducidos medios para hacer valer su autoridad, llevó a numerosos aventureros chilenos a establecerse en aquel territorio desde 1840 y a explotarlo sin autorización boliviana. Bolivia quiso solucionar estas infracciones, tratando de negociar con los emigrantes, sin embargo, Chile rehusó tratar el asunto en tanto avanzaba sobre territorio boliviano.

Así se llega al primer Tratado de Límites, suscrito entre ambas naciones el 10 de agosto de 1866 , fijándose como límite el paralelo $24^{\circ}$ de

3 Una región magra, un desierto sin agua, áspero y duro, que contenía ricos yacimientos de salitre, bórax y cobre. 
latitud sur. El mismo estipuló la mancomunidad de explotación del guano, los metales y minerales en el territorio comprendido entre los parale$\operatorname{los} 23^{\circ}$ y $25^{\circ}$ de latitud meridional. De esta manera, Chile logró llegar hasta el grado $24^{\circ} \mathrm{y}$ fue facultado para trabajar y explotar las riquezas hasta el grado $23^{\circ}$. Con este antecedente, el 6 de agosto de 1874, se firmó el segundo Tratado de Límites entre Bolivia y Chile. En virtud del mismo, se mantuvo la línea divisoria en el grado $24^{\circ}$ y los derechos de explotación chilena hasta el grado $23^{\circ}$ subsistían. También se acordó que las industrias chilenas no serían gravadas con impuestos durante 25 años. Un año después, el 21 de junio de 1875, fue firmado un Tratado Complementario al de 1874, que consignaba modificaciones de los artículos 30. y 10 e incorporaba una cláusula de arbitraje.

Poco tiempo después de ratificado el Tratado de 1874, una empresa británica pidió que se le aprobara una concesión para explotar salitre. El Congreso boliviano en 1878 impuso el pago de la suma ínfima de 10 centavos de boliviano por cada quintal de salitre exportado. El establecimiento de este impuesto suscitó una reclamación del gobierno de Chile, que sostenía la violación del tratado antes mencionado, pese a que el mismo únicamente favorecía a empresas chilenas y no a las británicas. El gobierno de Bolivia hizo saber que estaba llano a acogerse al recurso arbitral previsto en el tratado complementario. Como respuesta a la decisión boliviana, Chile optó por ocupar el puerto de Antofagasta el 14 de febrero de 1879 , localidad en la que Bolivia no contaba con fuerzas militares. Después de tomar Antofagasta, Chile ocupó los puertos de Cobija, Mejillones y Gatico, las poblaciones de Calama y San Pedro de Atacama y los yacimientos mineros de Caracoles. ${ }^{4}$

4 En abril de 1879, las jóvenes repúblicas sudamericanas del Pacífico: Bolivia, Chile y el Perú, que apenas treinta años atrás se habían enfrentado en la llamada Guerra de la Confederación por el predominio comercial en las costas del Pacífico Occidental, iniciaron uno de los conflictos más largos, cruentos y costosos en la historia de América Latina, cuyas causas radicaban en las políticas emprendidas por los gobiernos de La Paz y Santiago sobre el territorio de Atacama, entonces bajo soberanía boliviana. Poco después de emerger como Estados independientes, Bolivia y Chile mantuvieron diferencias en cuanto a los límites que los dividían en la franja costera. La interpretación chilena establecía que su territorio alcanzaba hasta el paralelo 23 de latitud sur, mientras que para los bolivianos el límite se fijaba en el paralelo 26. La situación se complicó cuando en las tierras en disputa se descubrieron importantes yacimientos de salitre, que era un codiciado nitrato utilizado como fertilizante y para la fabricación de pólvora. En 1866, “el gobierno dictatorial del general Melgarejo, que entonces regía los destinos de 


\section{Yendo un poco atrás cabe señalar que:}

La presencia chilena era abrumadora, su población superaba ampliamente a la boliviana y sus empresas dominaban la economía del lugar. La autoridad política boliviana era solo una ficción, lo que nos lleva a pensar que la toma de decisiones en cualquier plano para la estabilidad de Bolivia, era solamente un espejismo y reflejaba las necesidades chilenas y por ende, los beneficios no se quedaban en el país, sino que se exportaban hacia el país vecino. ${ }^{5}$

Debido a la falta de infraestructura ferroviaria o carretera, Chile y Perú comprendieron la gran importancia de obtener y mantener el control de las líneas de comunicaciones marítimas. El mar era la carretera para desplazar y apoyar los ejércitos en el área en disputa. La alternativa, una marcha por un desierto inhóspito, era tan ineficiente como peligrosa para las fuerzas terrestres. Además, el control del mar significaba la posibilidad de flanquear y envolver a las fuerzas enemigas, estrategia que Chile empleó posteriormente durante toda la guerra. Chile poseía una flota mayor y más joven que Perú. Los buques de combate chilenos más importantes, los acorazados Almirante Cochrane y Blanco Encalada, eran tecnológicamente avanzados para la época y llevaban sólo cinco años en servicio. A Perú le interesaba obtener las salitreras de Tarapacá, explota-

Bolivia, concedió cinco leguas de terreno en el desierto de Atamaca, para la elaboración del salitre a dos ciudadanos chilenos, Ossa y Puelma; concesión que fue seguida de otra a favor de la Sociedad Explotadora del Desierto de Atacama, fundada por los mismos Ossa y Puelma, "del privilegio exclusivo durante 15 años para la elaboración y libre exportación del salitre en el desierto de Atacama”. Ambos países habían zanjado sus diferencias territoriales mediante la suscripción del Tratado de Límites entre Bolivia y Chile de 1866, que estableció el paralelo 24 como límite, pero que acordó la división por partes iguales de las ganancias por el salitre explotado por empresas de capital chileno y británico entre los paralelos 23 y 25 . Sin embargo, el instrumento bilateral no resultaría satisfactorio para las nuevas autoridades bolivianas, quienes argumentaban que carecía de valor por haber sido suscrito por Mariano Melgarejo, un dictador aparentemente influenciado por intereses chilenos. En 1872 se realizó una revisión y en 1874 se firmó un nuevo tratado por el cual Chile renunció a los beneficios económicos de la explotación salitrera en la zona comprendida en los paralelos 24 y 25; de su lado, el gobierno de Bolivia se comprometió a no incrementar los impuestos sobre el salitre durante los próximos 25 años, esto es, hasta 1899. Alperovich y Sliezkin, Historia de América Latina, México, Ediciones Quinto Sol (consúltese el siglo XIX y principios del $\mathrm{XX}$, Cono Sur).

\section{Ibidem, p. 67.}


das por trabajadores y capital chilenos. Con el respaldo de un acuerdo secreto con Bolivia (1873), expropió las salitreras, pero como no tenía capital para comprarlas, fijó un sistema de pagos a largo plazo que después se negó rotundamente a cumplir.

En 1878, el presidente boliviano Hilarión Daza aprobó una ley que aumentó en diez centavos el impuesto a los empresarios chilenos que explotaban el salitre. Como se negaron a pagar, se dio la orden de embargar y rematar las salitreras chilenas, por lo que el presidente chileno, Aníbal Pinto, reaccionó ordenando la toma de Antofagasta el mismo día en que estaba previsto el remate (el 14 de febrero de 1879). En consecuencia, la escuadra chilena se apoderó del litoral boliviano hasta el río Loa, en el límite con Perú. ${ }^{6}$ En respuesta, Bolivia declaró la guerra a Chile el 1o. de marzo de 1879. Ante la solicitud del gobierno chileno de que se declarase neutral, Perú respondió que un tratado secreto lo unía con Bolivia. Así, le declaró la guerra a Chile el 4 de abril y éste a su vez, declaró la guerra a ambos países el 5 de abril de $1879 .{ }^{7}$

\section{Desarrollo progresivo y momentos críticos de la Guerra del Pacífico}

Dado lo inhóspito del territorio y la falta de transporte terrestre hacia y en la región en conflicto, la campaña marítima fue un componente principal de este conflicto denominado Guerra del Pacífico. Para asegurarse de que el mar se mantuviera abierto para mover sus tropas, Chile y Perú adoptaron estrategias congruentes con su poder naval relativo, y Chile buscó una batalla decisiva para obtener domino total del mar. Cuando el bloqueo del centro de exportación del sur del Perú, Iquique, no produjo los resultados esperados, Chile envío una fuerza concentrada al norte en busca del enemigo, Perú evitó una batalla a gran escala de ambas flotas

6 Chile había apelado al pretexto del impuesto de los 10 centavos del quintal de salitre exportado (por ello también se le llama la "guerra de los diez centavos"), que Bolivia había creado para gravar a la Compañía Anónima de Salitre y Ferrocarril de Antofagasta, constituida por capitalistas chilenos, y sostenía que era ilegal porque según el anterior tratado firmado entre ambos países, la exportación de salitre debía estar libre de todo gravamen.

7 Ibidem, p. 69. Para acceder a una visión ponderada de los hechos ocurridos en esta etapa crucial previa e inmediata a la Guerra del Pacífico, se recomienda consultar trabajos de historiadores bolivianos, chilenos y peruanos. 
completas, aceptando su posición de armada más débil. Además intentó interrumpir las líneas marítimas chilenas por medio de ataques a los convoyes más débiles y a las ciudades al sur del área disputada. Perú esperaba que Chile dispersara su flota con el objeto de ejercer protección a sus convoyes y de localizar a los atacantes; con esta maniobra la flota chilena se estaría exponiendo a ser batida en detalle. La preocupación acerca de los ataques peruanos, evitaba que las fuerzas chilenas interfirieran con los esfuerzos de reabastecimiento peruano.

Según Tomás Caivano, el desarrollo del conflicto se puede dividir en cinco fases principales:

Campaña marítima. En ella se dio el combate de Chipana (abril 12 de 1879), el combate naval de Iquique (mayo 21 de 1879), el combate de Punta Gruesa (mayo 21 de 1879), el combate nocturno de Iquique (julio 10 de 1879) y el combate naval de Angamos (octubre 8 del mismo año). La débil resistencia boliviana, escasamente había logrado entorpecer los movimientos de las tropas chilenas, para quienes el desafío más complejo sólo se inició con el traslado de las acciones a territorio peruano. Para ello, era indispensable neutralizar a los poderosos blindados que la armada de ese país disponía y que representaba un serio riesgo para el traslado por vía marítima de los contingentes militares. "Esta fase de la guerra, conocida como Campaña marítima, culminó en octubre de 1879 , con la captura del monitor Huáscar. Este hecho dejó a disposición de la armada chilena el control de la costa del Pacífico y permitió, además, que el resto de la guerra se desarrollara en suelo peruano". ${ }^{8}$

Campaña de Tarapacá. Aquí se dio la toma de Pisagua (noviembre 2 de 1879), la batalla de Dolores (noviembre 19 de 1879) y el combate de Tarapacá (noviembre 27 de 1879). La estrategia diseñada por el comando civil para las fuerzas armadas chilenas, consistía en que, protegidas por la artillería naval, las unidades terrestres debían desembarcar al norte de la región que se deseaba capturar. De esta manera, se impedían las comunicaciones con el resto del país y sometían la resistencia armada en conjunto con las tropas que, simultáneamente, avanzaban por tierra desde el sur. Esta maniobra fue puesta en práctica en noviembre de 1879, con el desembarco en Pisagua que permitió la captura de la provincia de Tarapacá y sus yacimientos salitreros.

8 Caivano, Tomás, La guerra de América entre Perú, Chile y Bolivia, Lima, Científica, 1979. 
Campaña de Tacna. Se desató la batalla de Tacna (mayo 26 de 1880) y la toma del Morro de Arica (junio 7 de 1880). En febrero de 1880, con el desembarco en Ilo, fueron conquistadas las ciudades de Tacna y Arica.

Campaña de Lima. La constituyeron las batallas de Chorrillos (enero 13 de 1881) y Miraflores (enero 15 de 1881), y la ocupación de Lima (enero 17 de 1881). En noviembre de 1880, con el desembarco en Paracas, el ejército peruano quedó dividido, facilitando la captura de Lima, ocupada en enero de 1881.

Campaña de la Sierra. Se dieron los combates de Sangra (junio 28 de 1881), de la Concepción (julio 9-10 de 1882) y de Huamachuco (julio 10 de 1883). La ocupación militar del Perú significó que la guerra entrara en una fase más compleja para las fuerzas armadas chilenas, puesto que debieron enfrentar a un enemigo organizado en guerrillas y montoneras, mucho más escurridizo que cuando tenía la forma de un ejército regular. La resistencia peruana estaba dividida en dos fuerzas: el Ejército de la Sierra, derrotado en Huamachuco, en julio de 1883, y el Ejército del Sur, doblegado en octubre de ese año, actividad bélica que marcó el fin del conflicto. ${ }^{9}$

La guerra de 1879, donde el ganador estuvo apoyado por Inglaterra como potencia extranjera con grandes intereses en la región, tuvo tres grandes consecuencias territoriales que van a dar origen al diferendo Bolivia-Perú-Chile que se prolonga hasta nuestros días: a) Chile mueve su frontera hacia el norte; en consecuencia, b) Bolivia pierde su acceso al mar; y c) Chile obtuvo como botín de guerra los principales yacimientos de nitrato tanto de Bolivia como de Perú. También es de destacar que si bien el conflicto produjo para Bolivia la perdida de su litoral, también originó el fin del caudillismo militar y sus guerras homicidas, y permitió el posterior desarrollo de una elite empresarial minera que desarrolló la

9 Chile luchó contra Perú y Bolivia en la Guerra del Pacífico entre 1879 y 1884; tal como en la Guerra Civil estadounidense y la Guerra franco-prusiana, este conflicto fue un encuentro militar importante en la segunda mitad del siglo XIX, debido a que se utilizaron tecnologías nuevas y conceptos operacionales militares evolucionados. Sin embargo, a diferencia de las dos guerras del norte, la conflagración del Pacífico implicó una campaña marítima inicial que contenía una mezcla de batallas del siglo XVIII y el uso de armas del siglo XX. Las operaciones para obtener y ejercer el control del mar incluyeron abordajes, fuego de artillería de largo alcance, ataques con torpedos, operaciones de minado, operaciones anfibias, bloqueos, batallas decisivas en el mar, ataques a líneas de comunicaciones comerciales y el desarrollo de técnicas submarinas. 
economía. Bolivia, el país con más golpes de Estado en la historia mundial, ha perdido la mayor parte de su territorio ante sus cinco vecinos y ha aceptado en diferentes tratados de paz y límites las consecuentes nuevas fronteras. Por otra parte, para principios del siglo XX, La Paz tiene diplomáticamente las manos desarmadas para reivindicar su anterior geografía costanera pues en octubre 1904, cedió a Chile la totalidad de su litoral oceánico a cambio de 300 mil libras esterlinas y de la construcción de un ferrocarril entre La Paz y Arica.

\section{Consecuencias inmediatas de la Guerra del Pacífico para cada uno de los beligerantes}

\section{A. Resultados para Chile}

Durante la controversia, el progreso de Chile no se interrumpió. La guerra estimuló el desarrollo de la importante economía industrial que sirvió en gran medida para abastecer al ejército en campaña. Asimismo, se aprovechó el estado de movilización del ejército para pacificar a los araucanos una vez que fue tomada la capital del Perú; hecho que posibilitó la colonización en Temuco y Villarica con chilenos e inmigrantes europeos. Terminada la guerra, Chile consolidó su presencia en el norte del país al aumentar su territorio; se convirtió en el más importante entre los países latinoamericanos de las costas del Pacífico y pasó a ser considerado como una potencia sudamericana. Con el aumento de su territorio se hizo además de valiosas riquezas naturales que impulsaron la actividad empresarial del país, además de que se incrementó la producción agrícola, el comercio de exportación y los ingresos del fisco. El presidente José Manuel Balmaceda (1886-1891) jugó el papel más importante en el desarrollo del país. En cuanto a las regiones de salitre, entre 1884 y 1886 se inició una primera alianza entre los productores para reducir la producción que se encontraba saturada en ese entonces. Pero la alianza no tuvo éxito y la provincia de Tarapacá reinició su actividad. Esta provincia y Antofagasta tuvieron un auge espectacular; los puertos de Iquique y Pisagua, entre otros, incrementaron la exportación de salitre y la importación de gran variedad de productos para sustentar a las comunidades mineras que habían nacido en el desierto de Atacama. 


\section{Al respecto, acota el historiador Jacinto López:}

Los ingresos principales de la nación provenían principalmente de la industria salitrera, pero su mercado internacional era muy inestable. Los chilenos debían tratar de recuperar el equilibrio entre oferta y demanda para estabilizar el mercado, pero la industria del salitre se encontraba casi totalmente bajo el control de los empresarios ingleses que no estaban preocupados por las necesidades de Chile sino únicamente por los intereses de sus accionistas y su propio beneficio. ${ }^{10}$

De esta manera, finalizada la guerra el gobierno se dedicó a planear una forma para reconstituir la propiedad de la industria del salitre y explotarla en beneficio de Chile así como de desarrollar otras regiones del país en el que la inmigración tuvo un papel decisivo. Efectivamente, el auge de las salitreras atrajeron hacia la economía regional a una gran cantidad de inmigrantes de todo tipo:

Trabajadores del Chile central, Bolivia y Perú, ingenieros y técnicos de Europa, en especial del Reino Unido, y comerciantes, banqueros y hombres de negocios; la población de Antofagasta pasó de 5,384 habitantes en 1875, a 21,213 diez años más tarde; la de Tarapacá de 39,255 a 45,086, en el mismo periodo; Iquique... experimentó un crecimiento que fue desde unos 9,200 hasta casi 16,000 habitantes. ${ }^{11}$

El esfuerzo de industrialización estimulado por la guerra logró un cambio en la economía chilena que trajo consigo una gran diversificación social y la creación de nuevas facciones políticas. Los aranceles sobre el salitre beneficiaron un importante gasto público destinado a obras públicas como la construcción de puertos y ferrocarriles, obras de carácter social (preferentemente la educación), y para reforzar las fuerzas armadas. La economía estaba mejorando en Chile por lo que Balmaceda tomó la nacionalización de las salitreras como el proyecto de nación, pues para 1889 las actividades del industrial salitrero más importante de

10 López, Jacinto, Historia de la guerra del guano y el salitre o Guerra del Pacífico entre Chile, Bolivia y el Perú, Milla Batres, 1979. Conmemorativa al primer centenario de la Guerra del Pacífico (se recomienda consultar toda la obra para una apreciación integral de este conflicto, donde puede observarse el verdadero papel que en el mismo jugó Inglaterra y sus inversionistas en Chile y Bolivia).

11 Ibidem, p. 87. 
Inglaterra en Chile, John North, advertían un intento de monopolio que representaba una amenaza tanto para los intereses de la provincia de Tarapacá como para el gobierno, cuya renta pública dependía cada día más del salitre. ${ }^{12}$

Aunque Chile ya estaba en camino de convertirse en una "economía nacional integrada" debido a la red de comunicaciones existente en todo el país desde hacía mucho tiempo, los ingresos por el salitre aceleraron el proceso de crecimiento económico. A partir de la Guerra del Pacífico se incrementaron el cultivo de trigo en el sur y la viticultura en el centro, y se expandieron las empresas industriales de producción de bienes de consumo. Hubo una tendencia creciente de los ingresos por tasas de exportación del salitre entre 1891 y 1920 que permitió a los gobiernos posteriores llevar a cabo grandes proyectos que favorecieron la creación de empleo y las demandas de consumo. ${ }^{13}$

\section{B. Resultados para Bolivia}

A reserva de la detallada referencia que haremos sobre este rubro en el apartado III del presente artículo y a modo de adelanto, hemos de señalar que a diferencia de Chile, a quien la Guerra del Pacífico convirtió en una importante nación sudamericana, para Bolivia representó uno de los acontecimientos más dramáticos. El ejército de este país fue totalmente derrotado por los chilenos, lo que le valió a Bolivia la pérdida del territorio más estratégico por significar su única salida al mar. Desde 1880 hasta hoy, la pérdida del acceso al mar ha sido el más grande problema al que esta nación se haya tenido que enfrentar.

12 Balmaceda necesitaba fomentar una mayor participación chilena en la industria, y de manera urgente. El presidente entonces se volcó hacia una política sobre la industria del salitre de menos intereses y control extranjero sobre ella con el fin de ampliar el papel del Estado en la economía nacional.

13 Para 1914, Chile ya era un país que poseía una industria manufacturera que podía proporcionar las necesidades principales del país e incluso exportar sus productos a sus vecinos. Aunque existía una gran cantidad de empresarios extranjeros, además de que una gran parte del capital del país provenía del exterior, la posesión de salitre y la buena reputación de los chilenos como buenos pagadores de deudas le valieron al país un lugar en las finanzas internacionales que facilitaron los créditos. Gracias a ello, Chile logró modernizar sus principales ciudades a través de mejoras en los transportes, los servicios de sanidad y la educación, así como con la construcción de grandes edificios e importantes obras de vialidad urbana. 
Si bien el crecimiento económico de Bolivia no se interrumpió después de la guerra, el territorio de gran contenido salitrero que perdió a manos de los chilenos no le permitió un despegue que rebasara al de sus vecinos, como le sucedió a Chile. Aunque Bolivia pudo crecer debido a la producción de plata, se enfrentó al problema de depender económicamente de un producto cuyo cambio de precio en el mundo tenía un impacto directo en la economía de la nación, el cual tuvo su mayor problema en 1900 con el colapso del metal en el mercado internacional (que también impactó a Perú y a México). El derrumbe de la economía boliviana por la abrupta caída de la plata pudo ser evitado debido a que la infraestructura existente logró ser transferida a otros metales; en esta transferencia, el estaño quedó en el lugar de la plata como la industria fundamental del país por un golpe de suerte: en ese momento las minas de estaño en Europa estaban agotadas y Bolivia pudo aprovechar esta situación y responder a la demanda. La historia consigna que a partir de ese momento los capitales provenientes de Europa, Estados Unidos de América y Chile compitieron con los capitalistas bolivianos por el control de las minas de estaño.

Pero la suerte de Bolivia volvió a cambiar con la llegada al poder del presidente liberal José Manuel Pando (1899-1904). Lo que más se recuerda de este periodo es otra pérdida adicional de una parte importante del territorio nacional. Primero en 1903 los bolivianos tuvieron que ceder Acre a Brasil, territorio que recaudaba grandes sumas de divisas por el caucho que se exportaba al gigante del Cono Sur. Después de este hecho el presidente terminó asumiendo la misma posición de los gobiernos anteriores que exigían de Chile la devolución de los territorios ocupados durante la Guerra del Pacífico, empero en 1904 antes de dejar el poder firmó un tratado con este país por medio del cual renunció a los territorios del litoral y a la demanda de un puerto en el gran Océano o un corredor hacia al mismo. ${ }^{14}$

Después de la Primera Guerra Mundial, la industria del estaño se recuperó espectacularmente, y en 1929 se alcanzó el máximo volumen de producción, Sin embargo, los precios comenzaron a descender con rapidez y hacia 1930 se manifestó una grave crisis en el sector: la época de

14 Gobierno de la República de Bolivia, El libro azul. El problema marítimo boliviano, La Paz, 2004, pp. 14 y 15. 
las grandes inversiones había terminado. ${ }^{15}$ Bolivia continuó siendo un Estado importador de productos alimentarios. El despegue del estaño fue positivo únicamente para un tercio del total de la población pues el resto del pueblo, principalmente las masas más empobrecidas, bajó sensiblemente su nivel de vida debido a la expansión del sistema de latifundios. La situación empezó a empeorar para el país a partir de la guerra del Chaco contra Paraguay que duró de 1932 a 1935 y provocó grandes pérdidas humanas y territoriales. Paraguay, otro país mediterráneo, se quedó con la absoluta mayoría del territorio del Chaco Boreal, completando la frustración y debilidad de Bolivia. En efecto, la derrota del ejército boliviano, que se suponía mejor preparado, provocó una gran decepción nacional y una profunda desconfianza hacia las jerarquías políticas y militares y hacia los poderes económicos. ${ }^{16}$

\section{Resultados para el Perú}

Para el Perú la Guerra del Pacífico significó “innumerables penalidades, humillaciones y, finalmente, la derrota nacional". Hasta el "boom del guano", a mediados del siglo XIX, Perú no había contemplado la posibilidad de la unidad nacional. Pero esa esperanza se terminó con el desenlace del conflicto armado contra Chile, que hundió al país en un periodo de total anarquía. Recordemos que al revelarse la gran importancia económica del desierto de Atacama, rico en yacimientos de salitre, estalló la rivalidad entre Bolivia y Chile (Inglaterra detrás de éste) por su posesión. El Perú estaba ligado a Bolivia por un tratado secreto, y entró automáticamente en guerra contra Chile cuando este país ocupó la ciudad entonces boliviana de Antofagasta. En mayo de 1879, en la batalla de Iquique, el Perú perdió su más importante buque de guerra, quedando su costa inerme ante la flota chilena. Como en el caso de Bolivia, a diferen-

15 Tras la revuelta de 1930, Daniel Salamanca ocupó la presidencia en 1931, si bien los cambios más importantes fueron los referidos a la situación económica, la crisis económica mundial provocó una reducción de los ingresos nacionales y el cierre de gran parte de las minas. Para hacer frente al malestar social y a la oposición política, se desvió la atención pública hacia el exterior, iniciándose un conflicto fronterizo con Paraguay por la posesión de la región conocida como Chaco Boreal. Véase Enciclopedia hispánica, vol. 3, México, 1991-1992, pp. 73 у 74.

16 De este descontento surgieron nuevos partidos de carácter socialista y radical. En 1936 se instauró el primer gobierno militar desde 1880, dirigido por jóvenes veteranos de la Guerra del Chaco, representantes del llamado socialismo militar. 
cia de Chile que no interrumpió su progreso durante la guerra, el Perú sufrió divisiones sociales irreconciliables. Por un lado estaban los campesinos indígenas quienes, viendo en la lucha una forma de emancipación, habían formado grandes fuerzas irregulares de guerrillas, apoyadas por el general Andrés Avelino Cáceres. Y por el otro, actuaban los terratenientes, quienes temían que las fuerzas indígenas pudieran volverse contra ellos. De esta manera las elites cambiaron su actitud hacia la guerra y pensaron que la negociación con Chile serviría mejor a sus intereses. Así llegó al poder el caudillo Miguel Iglesias, quien negoció en 1883 el tratado de paz con Chile.

Efectivamente, el Tratado de Ancón, firmado el 20 de octubre de 1883, finalizó la guerra del Pacífico, dejando en manos chilenas la provincia peruana de Taracapá y la administración durante diez años, de las de Tacna y Arica. La guerra con el extranjero había terminado pero en su lugar comenzó una guerra civil entre Iglesias y Cáceres, que terminó en 1885 con la capitulación de Iglesias. Cuando Cáceres tomó el poder, se encontró con un país económicamente agotado: todas las clases sociales estaban en la miseria. Las principales exportaciones del país habían sido el guano, el salitre y el azúcar; pero el bloqueo de Chile de todo el territorio donde se producían había llevado al Perú a la ruina. No obstante esto significó un obligado impulso hacia la modernización económica. Los siguientes años fueron para el Perú un periodo de profundos cambios en la sociedad de donde saldría la configuración sociopolítica del Perú actual. ${ }^{17}$

Después de la revolución popular que llevó a Nicolás Piérola a la presidencia, inaugurando un periodo de 24 años de gobiernos civiles, la economía peruana conoció una nueva expansión, gracias a la diversificación de las exportaciones. A las tradicionales de guano y nitratos se sumaron las de algodón, café, azúcar y petróleo. En 1902 se formó la compañía Cerro de Pasco, de capital estadounidense, que emprendió la explotación del cobre, un recurso muy abundante en el país inca. Durante el mandato de Augusto Leguía (1908-1912) se logró algo que no ocurrió en la negociación de Bolivia con Brasil: la firma de un ventajoso acuerdo de límites con Brasil (que años más tarde serviría de base al Tratado de

17 Selser, Gregorio, Cronología de las intervenciones extranjeras en América Latina, t. II: 1849-1898, México, 1995, colección Cuadernos del CEIICH, serie Fuentes. 
Río de Janeiro de 1942, por el que Perú obtuvo importantes territorios amazónicos reclamados por Ecuador). ${ }^{18}$

En 1929 un compromiso convencional dio por zanjada la larga disputa con Chile resultado de la guerra del Pacífico por las provincias del sur. Tacna volvió a manos peruanas, mientras que Arica permaneció en las del Estado chileno. Paralelamente, todos los esfuerzos de modernización económica se fueron abajo con la crisis económica mundial de 1929 que puso en cuestión la eficacia de una economía que hasta entonces había estado orientada únicamente hacia las exportaciones de materias primas y productos básicos estratégicos sólo para las potencias inversionistas y manufactureras, principalmente Estados Unidos de América. A partir de entonces Perú debió comenzar de nuevo su camino hacia la recuperación.

\section{TRATADOS, DECLARACIONES Y PROPUESTAS DE SOLUCIÓN, DESDE EL FIN DE LA GUERRA DEL PACÍFICO HASTA 1962}

\section{Tratados, notas y proposiciones desde 1879 hasta el fin de la Primera Guerra Mundial}

Antes de entrar en materia de tratados suscritos entre los beligerantes al término del conflicto marítimo, cabe recordar dos cartas escritas por el ministro Domingo Santa María, que después sería presidente de Chile, donde se pueden extractar algunos párrafos que revelan su visión sobre el problema generado a Bolivia. Llama a reflexión la fechada el 3 de diciembre de 1879 y que dice: "Dueños nosotros de todo el litoral boliviano y de todo el Departamento de Tarapacá, debemos dar un respiradero y una puerta de calle a Bolivia". La otra, dirigida a Rafael Sotomayor, ministro de Guerra en campaña, en noviembre de 1880, apuntaba: "No olvidemos que no podemos ahogar a Bolivia. Privada de Antofagasta y de todo el litoral que antes poseía hasta el Loa, debemos proporcionarle por alguna parte un puerto suyo, una puerta de calle, que le permita entrar al interior sin zozobra, sin pedir venia".

18 La contrapartida del desarrollo económico de Perú consistió en la penetración estadounidense en la economía peruana, sobre todo en la extracción de petróleo, y en el enorme crecimiento de la deuda externa. 
Santa María no concebía que Bolivia deviniera en un país mediterráneo y se preguntaba si Chile, sin consultar otro interés que el suyo propio, podía alterar el mapa americano.

\section{A. El Tratado de Ancón suscrito entre Chile y Perú} el 20 de octubre de 1803

Estableció la paz definitiva entre ambos países. El Perú le cedió a Chile la provincia de Tarapacá y se convino la realización de un plebiscito para definir la suerte de las dos provincias que quedaban en manos de Chile: Tacna y Arica. El plebiscito nunca llegó a efectuarse por la oposición de Chile. Con respecto a Bolivia, el gobierno chileno luego de suscribir el Tratado de Ancón comenzó a argumentar que no podía darle una salida al mar por su antiguo territorio porque, al anexarse la provincia peruana de Tarapacá, no podía dividir en dos la extensión territorial que había ocupado. Cualquier alternativa de solución debía plantearse al norte de Tarapacá y una vez definida la situación de Tacna y Arica.

\section{B. El Pacto de Tregua del 4 de abril de 1884}

Bolivia, ante la amenaza de nuevas hostilidades con las tropas chilenas concentradas en Puno, Tacna, Mollendo y Calama, se vio obligada a firmar este Pacto de Tregua, en la ciudad de Valparaíso. Los términos del mismo se mantuvieron en reserva hasta su aprobación por los parlamentos de ambos países. Por este instrumento, Chile justificó la ocupación de los territorios bolivianos conquistados durante la Guerra del Pacífico y asumió la administración de las aduanas que eran utilizadas por el Estado boliviano, apropiándose de sus recaudaciones como tributo de guerra. Junto con el pacto se firmó un protocolo complementario, el 30 de mayo de 1885. Ambos instrumentos eran totalmente favorables a Chile y fomentaron la expansión de productos chilenos en el mercado boliviano, con lo que el dominio de Chile fue total.

\section{Ley chilena y declaración que establece la anexión de Antofagasta}

En enero de 1887, el Senado de Chile discutió y aprobó un proyecto de ley que creaba la provincia chilena de Antofagasta, en el territorio correspondiente al Departamento del Litoral boliviano. El gobierno chileno 
aprobó la acción de dicha legislatura el 12 de julio de 1888, declarando la anexión de todo el Departamento del Litoral boliviano y creando la provincia chilena de Antofagasta sobre ese territorio. Las autoridades bolivianas protestaron, tanto por la discusión en el Senado chileno como por la creación de una provincia con base en territorios bolivianos que no habían sido cedidos por el Pacto de Tregua. Sin embargo, al final, Bolivia no pudo impedir la anexión de ese territorio. Antofagasta era una provincia rica en yacimientos de salitre y, hasta la Primera Guerra Mundial, la exportación de este producto, que se utilizaba para incrementar la productividad agrícola, se convertiría en una de las principales fuentes de ingresos para Chile.

\section{El Tratado de Paz y Amistad suscrito entre Bolivia y Chile, en 1895}

Ambas naciones estuvieron muy cerca de llegar a un acuerdo definitivo de paz en 1895, cuando ambos gobiernos firmaron cinco convenios interrelacionados. El primero del 18 de mayo, se refería a la consolidación del dominio de Chile sobre los territorios bolivianos ocupados y referidos en el Pacto de Tregua de 1884 y las obligaciones financieras emergentes de la guerra y la ocupación chilena. El segundo, indicaba la entrega de Arica a Bolivia, o en su caso, la Caleta Vítor, por parte de Chile una vez solucionado el diferendo entre Chile y Perú. El tercero, era de reglamentación comercial. Los otros dos convenios eran protocolos que reglamentaban los créditos y obligaciones económicas y la estipulación de que estos convenios constituían un "paquete integral" e indivisible entre sí. Estos tratados no entraron en vigor debido a que el congreso chileno no aprobó el quinto protocolo que hacía referencia a la indivisibilidad de los dos protocolos referentes a la transferencia de territorios y el restablecimiento de la paz.

\section{E. La nota "diplomática” de Abraham Köning, de 1900}

A comienzos del siglo XX, el gobierno de Chile decidió enviar a La Paz como ministro plenipotenciario a Abraham Köning. El 13 de agosto de 1900, este personaje envió una famosa nota-ultimátum al gobierno de Bolivia, la misma que la historia recordará como uno de los documentos menos diplomáticos e inamistosos de la historia latinoamericana, porque 
trató de consagrar, contra todo sentido jurídico y de manera cruda y determinista, el derecho de conquista. La nota textualmente decía:

Terminada la guerra, la nación vencedora impone sus condiciones y exige el pago de los gastos ocasionados. Bolivia fue vencida, no tenía con qué pagar y entregó el Litoral. Esta entrega es indefinida, por tiempo indefinido; así lo dice el Pacto de Tregua: fue una entrega absoluta, incondicional, perpetua... En consecuencia, Chile no debe nada, no está obligado a nada, mucho menos a la cesión de una zona de terreno y de un puerto (a favor de Bolivia). Es un error muy esparcido y que se repite diariamente en la prensa y en la calle, el opinar que Bolivia tiene derecho de exigir un puerto en compensación de su Litoral. No hay tal cosa. Chile ha ocupado el Litoral y se ha apoderado de él con el mismo título que Alemania anexó al imperio la Alsacia y la Lorena, con el mismo título con que los Estados Unidos de la América del Norte han tomado a Puerto Rico. Nuestros derechos nacen de la victoria, la ley suprema de las naciones... Que el Litoral es rico y vale muchos millones, eso ya lo sabíamos. Lo guardamos porque vale: que si nada valiera, no habría interés en su conservación.

La nota del ministro Köning fue entregada como un ultimátum al gobierno de Bolivia y, a la larga, estableció los términos del tratado de paz que suscribieron posteriormente ambos países.

\section{F. El Tratado de Paz y Amistad suscrito entre Bolivia y Chile, en 1904}

Bolivia con su litoral militarmente ocupado, sin puertos ni facilidades de tránsito, soportando la administración chilena de las aduanas bolivianas, no tuvo otra alternativa que aceptar los términos de un tratado impuesto por Chile el 25 de diciembre de 1903. El acuerdo fue rubricado en Santiago por los cancilleres Pinilla de Bolivia y Edwards de Chile, y en el mismo, se ratificaron los términos entregados por Köning en 1900. Posteriormente, el texto definitivo del Tratado de Paz y Amistad fue suscrito en Santiago, el 20 de octubre de 1904, con base en el documento de 1903. A cambio de la cesión de su Litoral, Chile le concedió a Bolivia un régimen de libre tránsito, una indemnización de 300,000 libras esterlinas y un ferrocarril de Arica a La Paz, con el tramo chileno bajo la administración de su gobierno. De esta manera, se consolidó la mediterraneidad boliviana. Después de la suscripción del Tratado de 1904, los esfuerzos 
de Bolivia para lograr retornar al Océano Pacífico, han sido permanentes e indeclinables.

\section{G. El memorando del canciller Daniel Sánchez Bustamante, de 1910}

El 22 de abril de 1910, este canciller boliviano, por órdenes del presidente Eliodoro Villazón, dirigió una circular a los representantes del Perú y Chile, en la cual exponía las justas aspiraciones del país y explicaba el deseo boliviano de conseguir una salida por Tacna o Arica, ambos territorios a la sazón chilenos en virtud al Tratado de Ancón, aunque con posibilidades de ser devueltos al Perú. Sánchez Bustamante decía: "Bolivia no puede vivir aislada del mar. Ahora y siempre, en la medida de sus fuerzas, hará cuanto le sea posible para llegar a poseer por lo menos un puerto cómodo sobre el Pacífico; y no podrá resignarse jamás a la inacción cada vez que se agite este asunto de Tacna y Arica que comprometen las bases mismas de su existencia". Más adelante, en el memorando se afirma: "El gabinete de La Paz estaría dispuesto a proponer bases y compensaciones satisfactorias a los de Santiago y Lima, siempre que ellos quisieran abrir las gestiones del caso, y que contemplasen la actitud de Bolivia con justiciero espíritu". A pesar del tono, la reclamación boliviana no prosperó, en gran parte porque la situación definitiva de Tacna y Arica no estaba resuelta, y permaneció así por casi veinte años más.

\section{La negociación: de la Sociedad de Naciones a la desviación} de las aguas del Río Lauca (1962)

Después de la Primera Guerra Mundial, se abrió la posibilidad de discutir el Tratado de Paz y Amistad de 1904. En la Conferencia de París de 1919 y en la Sociedad de Naciones en Ginebra en 1920, la delegación boliviana planteó la revisión del Tratado de 1904, junto a Perú, que pidió la revisión del Tratado de 1883. No obstante, Perú posteriormente retiró su petición. Por su parte, el gobierno de Chile afirmó que la Sociedad de Naciones no tenía competencia ni atribuciones para pronunciarse acerca de la modificación de instrumentos jurídicos internacionales. A pesar de ello, el delegado chileno Agustín Edwards ofreció, en forma solemne, ante la comunidad internacional, resolver el problema marítimo boliviano. A partir de ese momento se desarrollaron las siguientes iniciativas de solución. 


\section{A. El acta entre cancilleres del 10 de enero de 1920}

El diplomático Emilio Bello Codecido que, como canciller de Chile había suscrito el Tratado de 1904, visitó La Paz en 1920 para suscribir un acta con su homólogo boliviano Carlos Gutiérrez, donde se asentaba puntualmente que existía por parte del gobierno de Chile, el mayor deseo de propiciar una política del más sincero y estrecho acercamiento con Bolivia; y de procurar un acuerdo que le permitiera satisfacer su aspiración de obtener una salida propia al Pacífico. Con el propósito de cimentar sobre sólidas bases la amistad futura de ambos países, Chile estaba dispuesto a procurar que Bolivia adquiriera una salida al mar, cediéndole una parte importante de una zona al norte de Arica y de la línea dentro del ferrocarril que se hallaba en los territorios sometidos al veredicto del plebiscito, que debía realizarse de acuerdo con el texto del Tratado de Ancón. Finalmente, el instrumento no pasó de ser un catálogo de buenas intenciones.

\section{B. El memorando o Propuesta Kellog de 1927}

Posteriormente, el 30 de noviembre de 1927, el gobierno de Estados Unidos de América, por intermedio del secretario de Estado Frank Kellog, que mediaba en el diferendo peruano-chileno, después de considerar la injusta situación en que Bolivia había quedado al perder su soberanía marítima, envió un memorando a los gobiernos de Chile y Perú proponiendo: "ceder a la República de Bolivia a perpetuidad, todo derecho, título e intereses que ellos tengan en las provincias de Tacna y Arica". El gobierno de Chile accedió a considerar, en principio, la propuesta de Kellog, mientras que el Perú, contra lo que se esperaba en ese momento, rechazó la cesión de los territorios de Tacna y Arica. La gestión de Kellog estuvo muy cerca de lograr una solución definitiva a la cuestión de Tacna y Arica, y le permitió a Bolivia aproximarse a resolver su enclaustramiento.

\section{El tratado y su protocolo complementario entre Perú y Chile, de 3 de junio de 1929}

En vista de que el plebiscito previsto en el Tratado de Ancón, signado entre Chile y Perú, no se había efectuado, Estados Unidos de América promovió una negociación entre ambos países. En virtud de la misma, se 
acordó que Chile se quedaría con Arica y el Perú con Tacna. Bolivia se sintió afectada por este tratado porque en un protocolo complementario se estableció que los gobiernos de Chile y Perú no podían, sin un consentimiento previo, ceder a una tercera potencia la totalidad o parte de los territorios motivo del acuerdo. La referencia a una tercera potencia era una clara alusión a Bolivia. A partir de ese momento, en opinión del ex presidente boliviano Daniel Salamanca, Chile le puso el candado a la salida al mar de Bolivia y le entregó la llave al Perú.

\section{El intercambio de notas diplomáticas de 1950}

En junio de 1950, el embajador boliviano en Chile, Alberto Ostria Gutiérrez, y el ministro de Relaciones Exteriores de la República de Chile, Walker Larraín, intercambiaron importantes notas, en las que se propuso que sus gobiernos ingresaran formalmente en un proceso de negociación destinado a satisfacer la necesidad boliviana, a través de un corredor geográfico al norte de Arica. Dicha propuesta contó con la avenencia del entonces presidente chileno Gabriel Gonzáles Videla. Su gobierno expresó que estaba dispuesto a entrar formalmente en una negociación directa para dar solución a la salida libre y soberana de Bolivia, pero que, a cambio, solicitaba una compensación no territorial. La fórmula conciliatoria para Chile contemplaba:

Ceder a Bolivia, al norte de Arica, una faja de terreno de un ancho de diez kilómetros, contigua a la frontera peruana y que correría del litoral hasta el límite, para que Bolivia se pudiera comunicar con el Océano Pacífico, a través de su propio territorio y pudiera construir su puerto. A cambio de ello, Chile requería aprovechar las aguas del Lago Titicaca para generar energía hidroeléctrica que pudiera ser utilizada en las provincias de Tarapacá y Antofagasta.

De nueva cuenta, el intercambio de notas no reportó ningún avance.

\section{E. La intervención del presidente Harry Truman}

Tras diversas iniciativas internacionales de la diplomacia boliviana, que permitieron actualizar el problema de la mediterraneidad, el gobierno estadounidense presidido por Harry Truman propuso que, a través de medios pacíficos y negociaciones directas, Chile y Bolivia entrasen a 
considerar formalmente la cuestión de la salida al mar. En una asamblea de la OEA, Truman dijo que "las aguas de las elevadas montañas andinas" entre Bolivia y Perú podían servir para "hacer un jardín en la costa de Sudamérica, en el occidente de Chile y Perú, dando en cambio a Bolivia un puerto en el Pacífico". Estados Unidos de América estaba dispuesto a financiar el desarrollo de dicha región. Lamentablemente, las gestiones diplomáticas no prosperaron.

\section{F. El incidente del desvío de las aguas del Río Lauca, en 1962}

Este incidente es considerado un verdadero parteaguas en la historia de las negociaciones más importantes de la segunda posguerra. En efecto, en el marco de una tensa y difícil relación bilateral, en abril de 1962, el gobierno de Chile desvió, sin consentimiento de Bolivia, las aguas del Río Lauca, un río internacional de curso sucesivo. Bolivia acudió a la Organización de Estados Americanos (OEA), pero el organismo careció de efectividad para resolver el problema sometido a su instancia. Como consecuencia del desvío de las aguas del Río Lauca, se produjo la ruptura de relaciones diplomáticas entre ambos países.

\section{EL DESARROLLO DE LOS HECHOS Y LAS NEGOCIACIONES RELEVANTES EN EL PERIODO DE 1975 A 2006}

\section{Los hechos y las negociaciones relevantes de 1975 a 2000}

Damos inicio a esta etapa el 6 de agosto de 1975, cuando la OEA conmemoró el sesquicentenario de la creación de la República de Bolivia. En esta ocasión, se adoptó una declaración, que fue la primera referencia explícita de las naciones del hemisferio al problema del enclaustramiento marítimo. El texto de dicha declaración fue el siguiente:

El Consejo Permanente de la Organización de los Estados Americanos, formula lo siguiente:

La situación de mediterraneidad que afecta a Bolivia es motivo de preocupación continental por lo cual todos los estados americanos ofrecen cooperar en la búsqueda de soluciones que, de acuerdo con los principios del derecho internacional y especialmente con los contenidos en la Carta de la Organización de los Estados Americanos, ayuden a Bolivia a remover las dificultades que ha acarreado la situación de mediterraneidad para 
su desarrollo económico y social, conciliando intereses recíprocos y promoviendo entendimientos constructivos. ${ }^{19}$

Es destacable que, en dicha sesión, el delegado por Chile manifestó:

La delegación de Chile se asocia al sesquicentenario de la independencia de la República de Bolivia con un sentimiento de hermandad, formulando sus mejores votos por el progreso y bienestar de su pueblo. Compartimos con júbilo esta fecha histórica que es también de América, en la que culminó definitivamente la independencia política de los países de América del Sur... La delegación de Chile concurre con su aprobación a la Declaración que formula el Consejo Permanente con motivo de esta efemérides boliviana, y al hacerlo reitera el espíritu de la Declaración Conjunta de Charaña, manifestando una vez más su ánimo solidario.

Acto seguido, pasemos a revisar otros ejemplos relevantes de negociación en el periodo.

\section{A. Proceso de negociación entre 1975 y 1978}

En 1975, se inició un proceso negociador sobre un corredor y un enclave soberano, que implicó la reanudación de relaciones diplomáticas

19 El antecedente inmediato de esta declaración de la OEA en 1975, se encuentra en la Declaración de Ayacucho, pronunciada en Lima, Perú el 9 de diciembre de 1974, para conmemorar el 150 aniversario de la Batalla de Ayacucho, que pasó a la historia por haber puesto fin a la gesta independentista de América Latina; fue el último hecho de armas que puso fin a la guerra de independencia de las colonias latinoamericanas respecto de las metrópolis europeas. En ese acto se reunieron los jefes de Estado y de gobierno de Bolivia, Panamá, Perú y Venezuela, y los representantes de los jefes de Estado de Argentina, Colombia, Chile y Ecuador. La declaratoria comprende una serie de afirmaciones importantes para la causa de solidaridad, desarrollo e integración de los países centro y sudamericanos, entre las cuales vale la pena destacar el punto declaratorio correspondiente al diferendo Bolivia-Chile que aquí nos ocupa. Sobre el particular, se dice a la letra: "Al reafirmar el compromiso histórico de fortalecer cada vez más la unidad y solidaridad entre nuestros pueblos, prestamos la más amplia comprensión a la situación de mediterraneidad de Bolivia, situación que debe demandar la consideración más atenta hacia entendimientos constructivos". Después de leer tales argumentos, no deja de sorprender el gran divorcio que existe entre el mundo de las buenas intenciones y la retórica diplomática respecto del mundo objetivo de los intereses concretos y la real politik. Para mayor detalle consúltese los anexos de "Tratados históricos", en Gobierno de la República de Bolivia, op. cit., nota 14. 
entre Bolivia y Chile. El proceso se conocería como el Abrazo de Charaña y fue encabezado por el entonces presidente de Bolivia, general Hugo Bánzer, y el presidente de Chile, general Augusto Pinochet. El gobierno de Bolivia solicitó a Chile la cesión de una costa marítima soberana entre la línea de la Concordia y el límite del radio urbano de la ciudad de Arica. Esta costa debería prolongarse a través de una faja territorial soberana hasta la frontera boliviano-chilena, incluyendo la transferencia del ferrocarril Arica-La Paz. La respuesta chilena del 19 de diciembre de 1975 fue la siguiente:

Se funda en un arreglo de mutua conveniencia que no contendría innovación alguna a las estipulaciones del tratado de 1904. Chile estaría dispuesto a negociar la cesión de una franja de territorio al norte de Arica hasta la línea de la Concordia... La carretera a Tambo Quemado quedaría en territorio chileno... la cesión mencionada estaría condicionada al canje simultáneo de territorios... las instalaciones o construcciones estatales existentes en el territorio a ceder, deberán ser adquiridas por el Estado que recibe el territorio al precio de reposición (Aeropuerto de Chacalluta, FFCC Arica-Visviri, etcétera.).

Posteriormente, en virtud al Tratado de 1929, Chile consultó a Perú acerca de la propuesta, quien planteó la opción de un espacio geográfico "trinacional". Chile rompió las negociaciones, pese a que Perú ofreció flexibilizar su posición. En síntesis, en ocasión del Abrazo de Charaña, los tres países involucrados presentaron oficialmente sus respectivas posiciones; y en vista del fracaso de las negociaciones, Bolivia y Chile volvieron a romper relaciones diplomáticas en marzo de 1978.

\section{B. Resolución 426 de la Asamblea General de la OEA}

Al conmemorase el centenario de la Guerra del Pacífico, durante la X Asamblea General de la OEA, Bolivia obtuvo la Resolución 426, que se considera la más importante resolución en el marco multilateral. En la misma se señala puntualmente que la cuestión marítima es un asunto de interés hemisférico permanente y que es necesario encontrar una solución justa y equitativa que proporcione a Bolivia un acceso soberano y útil al Océano Pacífico. En otras palabras, la Resolución 426 acepta que la cuestión marítima no es un problema que únicamente afecte a Bolivia 
y Chile, y además se recomienda iniciar negociaciones para dar a Bolivia una conexión libre y soberana con el Océano Pacífico. ${ }^{20}$

\section{Otras resoluciones principales de la OEA}

Desde 1979 hasta 1989 se emitieron once resoluciones de la OEA sobre la cuestión marítima boliviana. En 1980, 1981 y 1983, Chile dio su apoyo a las resoluciones del organismo en la materia. En la resolución de 1980, se exhortó a ambos Estados que "a través de las vías correspondientes, inicien un diálogo que permita la solución más satisfactoria”. En 1981, también se exhorta a los Estados involucrados a que "a través de las vías correspondientes, inicien un diálogo que permita la solución más satisfactoria del problema marítimo boliviano". Finalmente, en 1983 y 1989, se exhorta a Bolivia y Chile a que "en aras de la fraternidad americana, inicien un proceso de acercamiento y reforzamiento de ambos pueblos... orientado a una normalidad de sus relaciones... incluyendo en especial una fórmula que haga posible dar a Bolivia una salida soberana al océano Pacífico sobre las bases que consulten las recíprocas conveniencias y los derechos e intereses de las partes involucradas". Generalmente, en el ámbito multilateral, ha existido la manifestación de voluntad del Estado chileno para comprometer el inicio de negociaciones para buscar una solución al problema marítimo de Bolivia; pero la realidad no pasó del terreno parlamentario como se puede constatar en distintas fuentes documentales. ${ }^{21}$

\section{Negociación 1986-1987: el proceso de "Enfoque fresco"}

En 1987, el gobierno del Uruguay ofreció su cooperación para que el tema marítimo se discuta y negocie en la ciudad de Montevideo. El proceso se conocería con el nombre de "Enfoque fresco". Para la ocasión, Bolivia retomó la idea del corredor y planteó la cesión de uno de los siguientes enclaves: caleta Camarones, Tocopilla y la caleta Michilla. Infortunadamente, en la respuesta del gobierno de Chile se rechazó la propuesta oficial presentada por Bolivia como base de negociación. El canciller de Bolivia presentó dos memoranda. En el primero, se solicitó a

20 Lamert, Jacques, América Latina: estructuras sociales e instituciones politicas, 3a. ed., México, Ariel, 1978.

21 Bethell, Leslie (ed.), Historia de América Latina. América Latina en la modernidad, Barcelona, Crítica, 2000. 
Chile ceder a Bolivia una costa marítima propia, soberana y útil, unida al territorio de Bolivia, mediante una franja soberana y útil, con límite norte la línea de la Concordia y como límite sur el curso del río Lluta hasta un punto al este de Coronel Alcérreca y desde ese punto una línea geodésica hasta el hito XI de la actual frontera entre Bolivia y Chile. En un segundo memorando, se plantearon tres alternativas de enclaves, en territorios no sujetos al Tratado de 1929: un enclave en Caleta Camarones hasta Pisagua, de Tocopilla hasta Cobija y de Caleta Mochila hasta Mejillones. El gobierno de Chile recibió la anterior petición en Montevideo, en reuniones efectuadas entre el 21 y 23 de abril de 1987 y comunicó que las mismas serían sometidas a la superior consideración de sus autoridades competentes. Así, conforme a lo previsto, el 9 de junio de 1987 Chile declinó considerar esa petición y ofreció estudiar paliativos a la mediterraneidad boliviana.

\section{E. El gobierno de Jaime Paz Zamora}

El presidente boliviano en turno habló con su colega chileno Patricio Aylwin acerca de la necesidad de resolver la cuestión marítima. Por otra parte, Bolivia aceptó suscribir un Acuerdo de Complementación Económica (ACE 22), que buscaba ampliar y diversificar el comercio de bienes y servicios entre los dos países, así como establecer un clima de confianza recíproca. Además, en 1989, el gobierno de Jaime Paz decidió dar un viraje al tratamiento del tema marítimo en la OEA, al obtener una resolución en la que se acuerda:

Reafirmar la importancia que tiene la solución del problema marítimo de Bolivia sobre bases que consulten recíprocas conveniencias y los derechos e intereses de las partes involucradas, para un mejor entendimiento, solidaridad e integración del hemisferio, exhortando al diálogo de las partes y dejando abierta la consideración del tema para cualesquiera de los próximos periodos ordinarios de sesiones de la Asamblea General a requerimiento de una de las partes involucradas.

Al final de este periodo gubernamental, se produjo un fuerte distanciamiento político entre ambos países. ${ }^{22}$

22 OEA, Memorias de la OEA, 1990-2000; Gobierno de la República de Bolivia, op. cit., nota 14. Desde 1990, Bolivia ha optado por presentar ante la Asamblea General de la 


\section{F. Los gobiernos de Gonzalo Sánchez de Lozada y Hugo Bánzer Suárez}

Durante el primer gobierno de Gonzalo Sánchez de Lozada se propuso la fórmula "sin condiciones pero tampoco con exclusiones". En seis ocasiones distintas se intentó abrir conversaciones para obtener una salida soberana al Pacífico, pero sin resultados. Finalmente, se produjo un acercamiento bilateral a través de emisarios confidenciales para hablar sobre la cuestión marítima; los mismos intercambiaron información y exploraron fórmulas de solución, que tampoco prosperaron. Por su parte, uno de los propósitos del gobierno de Bánzer fue insistir en la demanda marítima. En este contexto, los ministros de relaciones exteriores de Bolivia y Chile se reunieron en Algarbe (Portugal) y establecieron una nueva agenda de trabajo. A partir de esa reunión, hubo tres encuentros políticos al más alto nivel: los presidentes Hugo Bánzer y Ricardo Lagos se reunieron en Brasilia en septiembre del 2000, en Panamá en noviembre del 2000 y en Québec en abril del 2001. En el marco de esas reuniones, Bolivia y Chile establecieron una agenda, en la que se incorporaron todas las cuestiones esenciales de la relación bilateral "sin exclusión alguna". A fin de cuentas los logros fueron pocos y se entró en un nuevo impasse en la negociación por algunos meses.

\section{Las negociaciones y actos de gobierno relevantes de 2001 a 2004}

Después de la renuncia del presidente Hugo Bánzer Suárez, se hizo cargo de la primera magistratura de Bolivia, Jorge Quiroga Ramírez, que se reunió con el presidente de Chile, Ricardo Lagos, en noviembre del 2001 para proseguir las conversaciones sobre la nueva agenda bilateral. Uno de los objetivos centrales de la agenda externa del nuevo gobierno de Bolivia fue desarrollar el Proyecto Pacific LNG, cuyo objetivo era la exportación del gas natural boliviano por puertos del Pacífico al mercado estadounidense, aprovechando el proceso exportador para una mayor presencia y gravitación del país en el Pacífico a través de la creación de una zona económica especial. Durante el segundo gobierno de Gonzalo Sánchez de Lozada prosiguieron las negociaciones del Proyecto Pacific

OEA, informes anuales sobre la cuestión marítima para testimoniar el permanente daño que la mediterraneidad le causa a su economía y que representa significativas ganancias para Chile. En diversas oportunidades, a los informes que anualmente presenta Bolivia, se han adherido diversos países de la comunidad interamericana. 
LNG, sin haberse llegado a concretar las modalidades requeridas para hacer viable su implantación y desarrollo.

Posteriormente, el 24 de septiembre de 2003, en el marco de la Asamblea General de la ONU, el entonces vicepresidente de la República, Carlos Mesa, se refirió a la demanda marítima y pidió a Chile actuar a la medida de las circunstancias que exigía el siglo XXI. Ante el plenario de la 58a. Asamblea General de la ONU, Carlos Mesa se expresó en términos categóricos respecto de la añejo diferendo y la postura boliviana. ${ }^{23}$ Dos días después, ante el Consejo Permanente de la OEA, el vicepresidente boliviano se refirió a la necesidad de resolver urgentemente el problema de la venta de gas natural a EUA y México. Explicó asimismo la terrible crisis que azotaba a Bolivia y la violencia que se vivía y que estaba poniendo en juego la estabilidad democrática. Mesa dijo: "estamos viviendo una polarización del país, una radicalización de posturas y, por tanto, necesitamos un ejercicio de acercamiento, de diálogo y de voluntad de cesión de posiciones". Para Carlos Mesa no se debían plantear posiciones ultrarradicales cuando lo que se estaba decidiendo era el futuro del país. Con relación a la reivindicación marítima, recordó que Bolivia y Chile tienen una relación traumática no resuelta y en la que Bolivia demanda a Chile una posición de modernidad. Y afirma su postura señalando que la reivindicación boliviana no demanda, en opinión del gobierno de Bolivia, un sacrificio excesivo por parte de Chile, un país privilegiado en términos de kilómetros de costa y que además tiene, por naturaleza, una relación de complementación con el occidente de Bolivia y con el sur del Perú.

23 En esencia, declaró que: "Hoy más que nunca quiero reafirmar en este foro que Bolivia no renunciará a su justa reivindicación de un acceso soberano al Océano Pacífico, dado que nacimos como república independiente con litoral marítimo. Esta demanda que tiene ya más de un siglo, no es producto ni de terquedad ni de capricho, sino de la insuficiencia de nuestros recursos económicos y enormes obstáculos geográficos que nos restan competitividad. El enclaustramiento es un freno para nuestro crecimiento y el bienestar de nuestros ciudadanos, como se ha constatado en el análisis de los desafíos que enfrentan todos los países mediterráneos. La reintegración de la cualidad marítima es de justicia y para nosotros ineludible, por lo que seguiremos pidiendo solidaridad y apoyo de la comunidad de naciones. Nuestra vocación y nuestro destino de integración y complementación económica con nuestros vecinos, hace que exhortemos al gobierno y al pueblo de Chile a actuar mirando al futuro, reparando un daño histórico que nos tiene anclados en el siglo antepasado". Gobierno de la República de Bolivia, op. cit., nota 14, p. 53. 
Después de la crisis de octubre de 2003, la demanda marítima se reposicionó en el ámbito regional y multilateral. Ya como presidente, Carlos Mesa dirigió, el 4 de enero de 2004, un mensaje a los bolivianos y a la comunidad internacional planteando el tema en términos de que los acontecimientos de octubre tuvieron a la reivindicación marítima boliviana en el foco de la opinión mundial. Una de las preguntas centrales, en ese momento, era si se vendía o no el gas natural por un puerto chileno y, ante esta alternativa, gran parte de los bolivianos manifestó su oposición porque había un problema pendiente con Chile. Afirmó que antes de favorecer a un área determinada de ese país, el gobierno y el pueblo de Bolivia querían recuperar su soberanía marítima, dado que la reivindicación boliviana no es solamente un problema bilateral, y por ello los países vecinos y de la región se preocuparon porque la crisis boliviana pudiera extenderse hacia sus territorios. Terminó enfatizando que difícilmente mejorarán las relaciones bilaterales hasta que Bolivia vuelva a las costas del Pacífico y que en la eventualidad de que la solución del problema marítimo boliviano pase por una decisión del Perú, el gobierno de Bolivia espera que, a diferencia de lo ocurrido en el pasado, el Perú pueda dar una respuesta positiva.

Con este antecedente, durante la Cumbre Extraordinaria de las Américas, celebrada en la ciudad de Monterrey, México, en enero de 2004, el presidente Carlos Mesa afirmó "miramos al futuro con fe, convocamos al presidente Lagos y al gobierno de Chile a buscar con nosotros una solución definitiva a nuestra demanda marítima... las buenas relaciones internacionales pasan por la necesidad de resolver cuestiones que, por una razón de justicia, deben resolverse". Posteriormente, el primer mandatario indicó que la reanudación de relaciones diplomáticas entre Bolivia y Chile se concretará en el momento en que se haya resuelto definitivamente el problema marítimo y que no será el comienzo, sino el final del proceso de negociación. En respaldo a esta postura el congreso boliviano, en sesión especial efectuada el 20 de enero de 2004, declaró su firme convicción de que la reivindicación marítima es un derecho irrenunciable del pueblo de Bolivia que debe hacerse valer en el escenario internacional, manifestando reconocimiento a gobiernos y sociedades a nivel regional y mundial por el apoyo brindado a la causa. ${ }^{24}$

24 En paralelo, se dio una resolución de ese parlamento donde asienta que la República de Bolivia no ha renunciado ni renunciará a su legítimo derecho de retornar al 
Acto seguido se dio la Declaración Conjunta de los presidentes de Bolivia y Brasil del 8 de julio de 2004, en el marco del encuentro que mantuvieron en Santa Cruz de la Sierra los mandatarios de Bolivia, Carlos D. Mesa Gisbert y de Brasil, Luiz Inácio Lula da Silva. Entre los arreglos declarados están los siguientes: a) Reforzamiento de la asociación estratégica en el área energética, y aumento de las exportaciones de gas al Brasil y de las inversiones brasileñas en Bolivia en el sector de hidrocarburos; b) Instalación de la Comisión Ejecutiva Binacional del polo gas químico Brasil-Bolivia para el progreso de las áreas limítrofes y la industrialización del gas boliviano; c) Impulso a los proyectos conjuntos de aprovechamiento del Río Madera que, entre otros propósitos, permitirá a Bolivia acceso permanente al Océano Atlántico, toda vez que no lo tiene asegurado hacia el Océano Pacífico; revertir las restricciones que enfrenta el transporte de carga boliviana en tránsito hacia los puertos de Corumbá y Ladario; y, d) Acelerar las negociaciones para hacer posible el acceso franco de Bolivia a puertos y aeropuertos brasileños, con miras a promover el comercio exterior y aumentar la competitividad de la economía boliviana. Cabe hacer notar que estos acuerdos están siendo continuados por parte del actual gobierno boliviano de Evo Morales.

En este mismo orden de negociación, tuvo lugar después un comunicado conjunto de los presidentes de Bolivia, Carlos D. Mesa Gisbert, y del Perú, Alejandro Toledo Manrique, el 4 de agosto de 2004, en el escenario de la suscripción, en lo del Tratado General de Integración y Cooperación Económica y Social para la Conformación de un Mercado Co-

mar. Recuerda que Chile es el único país del hemisferio con el que Bolivia no tiene relaciones diplomáticas, lo que demuestra la existencia de un problema. Afirma que el país posee importantes reservas de gas natural, las cuales no pueden ser exportadas directamente por carecer de un puerto propio. Finalmente, en el documento se manifiesta que la demanda marítima es un asunto que debe abordarse de manera bilateral y trilateral, a la hora de buscar una solución definitiva al problema, y multilateral, al ser un asunto de interés hemisférico e internacional. Con estos argumentos, el congreso decidió conformar una Comisión Especial, encabezada por las Comisiones de Relaciones Exteriores de ambas cámaras, para coordinar permanentemente con el Ejecutivo todas las acciones que corresponda realizar, con el objetivo de lograr la reivindicación marítima y dar a conocer en todos los foros parlamentarios a nivel regional, continental y mundial, la justa causa marítima de Bolivia, demandando su apoyo y solidaridad para la solución del enclaustramiento del país. Nunca antes, al menos en los últimos lustros, se había mostrado la unidad ni la unanimidad con la que se aprobaron la declaración y la resolución sobre la demanda marítima. 
mún. Entre los puntos acordados, destacó la celebración de una carta de intenciones bilateral para la complementación energética, la exportación de hidrocarburos de Bolivia a través de un puerto peruano y el establecimiento de una zona económica especial que el Perú otorgará para ese fin. Ahora bien, para implementar lo acordado, se decidió formar una Comisión Mixta Especial presidida por las cancillerías de ambos países, que continúa funcionando hasta la fecha y sobre la cual se ha informado en fecha reciente que ha arrojado resultados concretos, específicamente en cuanto al proyecto de salida portuaria vía peruana a los productos bolivianos de exportación.

\section{La situación actual en la perspectiva de los gobiernos de Evo Morales en Bolivia y Michelle Bachelet en Chile (2005-2006)}

Desde los orígenes de la controversia, hasta el momento de escribir estas líneas, la reintegración marítima es un objetivo permanente e irrenunciable de la política exterior boliviana. Ya se dijo que Chile es el único país del hemisferio occidental con el que Bolivia no tiene relaciones diplomáticas, lo que demuestra la existencia de un problema pendiente. Es indudable que de producirse un acercamiento y una negociación favorable entre Bolivia y Chile a partir de 2006, la reanudación de relaciones será el corolario de una negociación satisfactoria y exitosa que Bolivia ha buscado a lo largo del siglo XX y en los años iniciales del XXI. En 2005 y 2006, el panorama político ha cambiado de manera importante con el arribo al poder de los presidentes Juan Evo Morales Aima en Bolivia, Verónica Michelle Bachelet Jeria en Chile (ambos de tendencias políticas de izquierda) y Alán Gabriel García Pérez en Perú (del centro derecha), tres nuevos dirigentes de los tres países involucrados en este diferendo irresuelto desde hace más de 130 años. ${ }^{25}$

Las elecciones de diciembre de 2005 reafirmaron lo que se venía gestando desde hace años: Evo Morales, del partido Movimiento al Socialismo (MAS) obtuvo el 54 por ciento de los votos, frente al 28 de su gran rival, Jorge Quiroga, de tendencia conservadora. Es la primera vez

25 Bachelet se convirtió en la sexta mujer jefe de Estado en la historia de Latinoamérica, después de la nicaragüense Violeta Chamorro, la argentina María Estela Martínez de Perón, la boliviana Lidia Gueiler Tejada, la ecuatoriana Rosalía Arteaga y la panameña Mireya Moscoso y la segunda elegida democráticamente en Sudamérica tras la guyanesa Janet Jagan. 
en la historia que un indígena se sienta donde sólo hasta ese entonces lo habían hecho generaciones de blancos. Sin haber hecho gabinete aún, en sus primeros días como presidente electo, Morales puso a Bolivia como protagonista del escenario internacional. Esa nueva historia comienza con la reivindicación del litoral perdido y la nacionalización de hidrocarburos que, a su juicio, no implica una confiscación de activos transnacionales sino un retorno del Estado a la producción y comercialización de petróleo y gas, revirtiendo la privatización efectuada en 1996. A esto se suma un control total de la actividad de las compañías extranjeras, sometidas al pago de impuestos "que sumen al menos 50\%" del valor del producto, especialmente gas natural, la mayor riqueza del país (con reservas estimadas en 48,700 millones de pies cúbicos, las segundas del Cono Sur, y $0.4 \%$ de la producción mundial). Evo Morales ha venido repitiendo desde que asumió el poder a principios de 2006 que el pueblo de Bolivia sufre cotidianamente el costo de la mediterraneidad; así, señaló en un discurso reciente que en la actualidad, pese a poseer enormes reservas gasíferas, al carecer de un puerto propio, Bolivia no puede exportar directamente dichas existencias para beneficiar a su población, por lo que iniciará negociaciones directas con la presidenta Bachelet sobre el asunto de la salida al mar, para lo cual propondrá la creación de una comisión binacional permanente (agosto de 2006). ${ }^{26}$

Por su parte, Michelle Bachelet, ex ministra de defensa, miembro del partido socialista chileno y candidata de la Concertación, la coalición de partidos que lleva tres periodos sucesivos en el poder desde la restauración de la democracia tras el mandato de Augusto Pinochet, asume la presidencia de Chile el 11 de marzo de 2006; convirtiéndose en la primera mujer presidente de Chile en sus 196 años de independencia. Su primer viaje oficial al extranjero en calidad de jefe de Estado lo realizó a Argen-

26 A la altura de agosto de 2006 el panorama de una negociación bilateral no parece ser muy propicio, más aún cuando algunos funcionarios chilenos han hecho declaraciones que muestran la actitud común y la desinformación del nuevo gobierno hacia el problema. Por ejemplo, un alto funcionario que pidió no ser identificado "para evitar malas interpretaciones" expresó que: "El impasse con Bolivia se resolverá cuando los políticos bolivianos dejen de usar la ignorancia de su pueblo encendiendo pasiones nacionalistas para ocultar su corrupción y fracaso. Chile le da mucho a Bolivia, la cual si tiene acceso al mar es gracias a carreteras y tren construidos por Chile y uso gratis de puertos" (Entrevista de BBC, enlace por David Álvarez, experto en ciencias políticas de la Facultad Latinoamericana de Ciencias Sociales, Santiago de Chile). 
tina y Uruguay, llegando al primer país el 21 de marzo, reuniéndose con su par argentino Néstor Kirchner, con quien firmó un acuerdo estratégico que tiene como puntos fundamentales: fomentar la cooperación mutua en materia energética (Chile tiene problemas de abastecimiento energético y depende en gran parte del gas argentino) y avanzar en la construcción de obras de infraestructura que mejoren los vínculos entre las dos naciones, como la licitación internacional del tren trasandino.

Entre tanto, el 23 de marzo, el gobierno de Bolivia conmemoró su Día del Mar bajo el supuesto de su actual presidente de que el gobierno de Bachelet aceptaría iniciar conversaciones sobre la exigencia boliviana de recuperar un derecho histórico perdido por una guerra injusta y obtener en consecuencia una porción de litoral en el Pacífico. Sin embargo, ese mismo día, el ministro de Relaciones Exteriores Alejandro Foxley Rioseco (demócrata cristiano) reafirmó la postura tradicional de la política exterior chilena, esto es, que no se pondría en duda la inviolabilidad de los tratados, y más específicamente, el de Paz y Amistad signado entre Chile y Bolivia en 1904. Poco tiempo después, surgió un nuevo problema con Bolivia cuando el gobierno de Morales decidió nacionalizar los yacimientos de hidrocarburos de su país, decreto que no complació a Chile, cuyo déficit energético es del $70 \%$.

\section{BALANCE GENERAL DE LOS COSTOS DE LA MEDITERRANEIDAD DE BOLIVIA}

\section{Los costos geográficos y económicos de la Guerra del Pacífico} para Bolivia

En el apartado I del presente estudio hicimos una primera descripción de este impacto, restando ahora precisar los principales daños geográficos y económicos que la guerra contra Chile le causó a Bolivia. Ante todo, en términos geopolíticos, significó el cercenamiento de $158,000 \mathrm{~km} 2$ de su territorio costero, o sea una superficie superior a las de Cuba, Jamaica, Trinidad-Tobago y El Salvador, sumadas. Esa simple comparación revela la magnitud de la pérdida. Pero el daño fue aún mayor en el aspecto económico. En el territorio cercenado, fueron descubiertos, a fines del siglo XIX, los fabulosos yacimientos cupríferos de Chuquicamata, considerados entre los más importantes del mundo. Gracias a ellos, Chile se convirtió en el primer exportador mundial y en el 
segundo productor de cobre después de Estados Unidos de América. Como lo expresara el ex presidente chileno Salvador Allende, el cobre se convirtió en "el sueldo de Chile".

Hasta la fecha, Chile ha exportado más de 20 millones de toneladas de cobre, cifra difícil de ser evaluada con precisión, pero que puede compararse con las reservas de todo el continente asiático, equivalente a cerca de 1.5 millones de toneladas, a las que habría que agregar las reservas de toda Europa Occidental, calculadas en casi 2.3 millones de toneladas, y de la Unión Soviética, alrededor de 16 millones de toneladas. ${ }^{27}$ Otro costo de la guerra fue pérdida de los yacimientos de guano, fertilizante natural depositado por aves marinas en el transcurso de siglos. Se calcula que en los últimos 50 años, Chile extrajo de las covaderas de guano fósil más de un millón de toneladas de fertilizantes para los campos agrícolas de las zonas central y sur de territorio. El uso intensivo de estos fertilizantes es fundamento de la alta productividad agrícola de la industria vitivinícola chilena de los últimos 40 años. Al guano hay que agregar los depósitos de nitrato de sodio (salitre) existentes en la antigua provincia peruana de Tarapacá y en la provincia boliviana de Atacama. ${ }^{28}$

27 En otros términos, durante el siglo XX y lo que va del XXII, Chile ha exportado tanto cobre como el que acumulan en sus territorios varios continentes juntos. Todo esto sin contar ingentes reservas que se vienen descubriendo. Se estima que, al ritmo actual de explotación, las minas de Chuquicamata no se agotaran hasta fines del siglo XXI. El botín que Chile ganó con la Guerra del Pacifico no se redujo a su expansión territorial y a la explotación del cobre, sino que se extendió al aprovechamiento extensivo, otras materias primas y metales estratégicos.

28 A partir de 1880, consumada la ocupación militar de la referida provincia boliviana, Chile exportó anualmente unas doce mil quinientas toneladas de salitre, cuyo valor alcanzó, más o menos, al $20 \%$ del total de ingresos provenientes de sus exportaciones. Si bien la invención del salitre sintético, en los primeros años de este siglo, redujo a cantidades mínimas el consumo internacional del salitre natural, hasta entonces las exportaciones chilenas de salitre y de su derivado, el yodo, financiaron cerca del 70\% de los ingresos fiscales del país. Hasta poco antes de la primera guerra europea, Chile tuvo al monopolio mundial de la producción de salitre. Actualmente, aún se hallan en actividad, en esa antigua provincia marítima boliviana, algunas empresas salitreras de mediana importancia. Cabe mencionar, asimismo, que en el presente, Chile produce cerca de diez mil toneladas de azufre. Algunos de los principales depósitos se hallan en el distrito de Ollague, ubicado en la ex-provincia boliviana de Atacama. Al azufre se agregan depósitos de molibdeno, manganeso, litio, hierro y plata, existente en cantidades varias en dicho territorio. 
Por otra parte, como consecuencia de la pérdida de su litoral, Bolivia no puede acceder a las riquezas y recursos naturales de los fondos marinos y no disfruta del beneficio económico originado por la venta de productos del mar, minerales o petróleo. Al privársele de su costa se la privó también de la riqueza ictiológica y de los recursos naturales de los fondos del mar. ${ }^{29}$ El país además tiene desventajas muy significativas para participar del comercio de servicios y el transporte marítimo con flotas de propiedad nacional y con bandera boliviana. También cabe destacar que parte del progreso y la prosperidad del norte de Chile es atribuible al comercio con Bolivia. En este contexto, por ejemplo, es importante señalar que $80 \%$ de la carga movilizada por el puerto de Arica es boliviana, que los productores mineros utilizan el puerto de Antofagasta y que gran parte del contrabando que afecta a Bolivia proviene de la Zona Franca de Iquique. La ciudad de Antofagasta debe su progreso y prosperidad, especialmente, al comercio con Bolivia, puesto que es uno de los puertos forzosos, en territorio chileno, para las exportaciones e importaciones bolivianas, donde la elevación unilateral y arbitraria de las tarifas ferroviarias es constante.

Otra consecuencia de la guerra y que se consolida con el Tratado de 1904 es que en todos los puertos chilenos las mercaderías bolivianas están sometidas a permanentes condiciones de deterioro y sustracción. Los altos costos de transporte y servicios que Bolivia debe soportar, le impiden acceder a los mercados internacionales en condiciones similares a otros países con costa marítima, situación que la hace perder competitividad. Las exportaciones nacionales además deben absorber los costos derivados del sistema integrado de transporte para acceder a los puertos. Asimismo, Bolivia no ha podido desarrollar, entre otras actividades, industrias derivadas de los productos marinos, las cuales tienen un significativo dinamismo en el comercio mundial y obtienen buenos precios internacionales. Tampoco se han podido establecer servicios e industrias vinculadas a la actividad naviera como, por ejemplo, astilleros, la industria naval, los servicios portuarios, el practicaje-pilotaje y el almacenamiento (silos, depósitos, patios, etcétera). Por consiguiente, la pérdida del litoral boliviano no representó solamente para Bolivia una desmembración cualitativa, cuya implicación más importante es la de haber

29 Montenegro, Walter, Oportunidades perdidas, La Paz, Los Amigos del Libro, 1987. 
dejado de ser un país costero comunicado directamente con el mundo, sino una disminución cuantitativa de la dotación original de recursos naturales existentes en ese territorio.

\section{Perjuicios económicos originados por el Tratado de 1904}

En virtud del Tratado de 1904, Bolivia se vio obligada a ceder su Litoral a perpetuidad a Chile a cambio de compensaciones que Chile debía cumplir. Estas compensaciones no han sido cumplidas por el gobierno chileno principalmente en los siguientes aspectos.

\section{A. El reconocimiento chileno a favor de Bolivia "y a perpetuidad, del más amplio y libre derecho de tránsito comercial por su terri- torio y puertos del Pacífico"}

El gobierno de Chile menciona en innumerables foros los beneficios del régimen de libre tránsito otorgado en favor de Bolivia. Sin embargo, olvida mencionar que, a pesar de que el Perú tiene una larga faja costera, Chile le ha concedido una serie de facilidades de tránsito en Arica, que Bolivia, un país mediterráneo, no posee. En efecto, en virtud del Acta de Ejecución de 1999, Chile le otorgó al Perú, el otro país involucrado en la Guerra del Pacífico, tres facilidades con las que Bolivia no cuenta: una agencia aduanera, un muelle de atraque y una estación terminal para el ferrocarril. Por otra parte, cabe destacar que las exportaciones bolivianas asumen un costo por pasar la frontera, la circulación de dichas mercaderías por puertos chilenos no es gratuita, y las disposiciones del Tratado de 1904 y las otros acuerdos complementarios no son cumplimentadas permanentemente por razones administrativas, sanitarias, de seguridad y otras, motivando constantes quejas por parte de los usuarios bolivianos en los puertos. ${ }^{30}$

30 Autoridades e instituciones chilenas hacen cobros excesivos e injustificados a los transportistas bolivianos. Asimismo, se realizan cobros arbitrarios por el servicio de transferencia de contenedores en tránsito (Gate in-Gate out, Tack) y por el traslado (devolución) de contenedores vacíos desde el puerto hasta los depósitos navieros. Desde la concesión del Puerto de Antofagasta a la Empresa Antofagasta Terminal Internacional (ATI), producida el 1o. de marzo del 2003, la mercadería de exportación boliviana ha venido sufriendo un incremento en las tarifas de porteo de minerales a granel, que representa un aumento de un $26 \%$ por tonelada. A esto se suma el doble manipuleo de la carga desde el centro de acopio en Portezuelo - ubicado cerca de la ciudad de 
Asimismo, el tránsito de las mercaderías desde y hacia Bolivia por territorio chileno no siempre ha sido "amplio y libre". Al contrario, se sabe de numerosos casos en que las autoridades chilenas han restringido o impedido este derecho. El caso que afectó más a los intereses de Bolivia se produjo durante la Guerra del Chaco, cuando las autoridades chilenas impidieron el tránsito de cargas destinadas a Bolivia, cometiendo una infracción al Tratado de 1904 y a la Convención de Tráfico Comercial del 6 de agosto de 1912. En forma similar, las autoridades chilenas, mediante actos administrativos unilaterales, inmovilizaron los embarques de minerales a los mercados mundiales como consecuencia de la nacionalización de las minas decretada por Bolivia el 31 de octubre de 1952. Además, en ocasiones, el tránsito de la carga boliviana se ha visto afectada como consecuencia de disturbios laborales en Chile, por ejemplo, huelgas o paros de protesta en el gremio de los trabajadores portuarios en Arica o Antofagasta.

Por otra parte, Chile viene implementando un proceso de privatización de sus puertos, que también está afectado el régimen de libre tránsito de las mercancías bolivianas. El proceso de privatización vulnera el espíritu del régimen de libre tránsito, el mismo que se enmarca en el Tratado de 1904 y las convenciones de 1912 y 1936. Los derechos bolivianos de libre tránsito son, a la vez, obligaciones internacionales del Estado de Chile, de tipo intuito personae, por lo que no pueden ser transferidas a un agente privado. Se trata de responsabilidades intrínsecas del Estado chileno. Desde la perspectiva del derecho internacional, las empresas privadas concesionarias no pueden ser sucesoras de las obligaciones que la República de Chile tiene con el Estado boliviano. Además, en el caso de la privatización del puerto de Antofagasta, se han incrementado sensiblemente los costos de las exportaciones de minerales, aspecto que ha incidido notoriamente en la competitividad de este sector productivo. La próxima licitación del puerto de Arica preocupa aún más, porque al licitarse todos los sitios de atraque se estaría estableciendo un monopolio que seguramente incrementará el costo de los servicios que se

Antofagasta - hasta el puerto, lo que representa un costo adicional a los empresarios bolivianos de dos dólares americanos por tonelada y el costo de almacenaje a la carga IMO. Debido a este apreciable encarecimiento, varias empresas mineras bolivianas se han visto obligadas a dejar de exportar minerales. Consultar: Comisión Andina de Juristas, op. cit., nota 1. 
prestan en este puerto, en el que la carga boliviana representa el $80 \%$ del total de la carga movilizada.

B. El Tratado de 1904 establece que: "La República de Bolivia tendrá el derecho de construir agencias aduaneras en los puertos que designe para su comercio. Por ahora, señala por tales puertos habilitados para su comercio los de Antofagasta y Arica”,

En aplicación de estas disposiciones y bajo el marco del Sistema Integrado de Tránsito, en los puertos de Antofagasta y Arica funciona una agencia aduanera boliviana, representada por la Administración de Servicios Portuarios-Bolivia (ASP-B), que se encarga de supervisar la operación y almacenaje de la carga boliviana en tránsito, así como de controlar el transporte de mercaderías con destino a Bolivia proveniente de ultramar. La privatización de los puertos limita también la presencia de ASP-B y el control que ésta ejerce sobre la carga boliviana en virtud de los acuerdos vigentes. Asimismo, cabe destacar que, aunque el Tratado de 1904 establece a favor de Bolivia el más amplio y libre derecho de tránsito por el territorio y puertos del Pacífico chilenos, las autoridades de este país se han mostrado reacias y han retrasado el tratamiento de las solicitudes de Bolivia para habilitar nuevos puertos para su comercio exterior además de los de Antofagasta y Arica.

\section{Ambos países reconocerían y respetarían los derechos} de los ciudadanos "nacionales y extranjeros que hubieren sido legalmente adquiridos en los territorios que, en virtud de este tratado, quedan bajo la soberanía de uno u otro país"

El artículo 2o. del Tratado de 1904 protegía a aquellos ciudadanos bolivianos que tenían propiedades en los territorios que, en virtud del mismo, quedaron bajo la jurisdicción de Chile. Infringiendo este artículo 2o., las autoridades chilenas dictaron una ley que obligaba a los ciudadanos bolivianos "a presentarse ante las autoridades a defender sus derechos por el término de cuatro meses desde la vigencia de esa ley". Cabe destacar que la propia Corte Suprema de Chile, violando los derechos de los propietarios bolivianos de las Salitreras del Toco, falló incumpliendo lo estipulado en el Tratado de 1904. Esto puede ser constatado y fácilmente corroborado en diversos documentos oficiales de los dos países en controversia. 
En el ámbito político, las reclamaciones de Bolivia por una salida al mar son utilizadas frecuentemente por los gobiernos de Chile para fines internos, buscando consensos y respaldo doméstico. En ese mismo orden de argumentación, es paradójico recordar que un gobierno militar chileno, el del dictador y presunto genocida Augusto Pinochet Ugarte, tuvo mayor coraje que los gobiernos democráticos que le sucedieron para reconocer el problema marítimo, buscando establecer una solución definitiva al tema. Dicha negociación fracasó, entre otros motivos, porque la oposición interna en el vecino país consideraba que estos problemas debían ser solucionados precisamente por dichos gobiernos democráticos, que supuestamente tenían mayor apoyo y legitimidad. Sin embargo, a pesar de que la transición democrática en Chile se produjo hace más de una década, el problema marítimo boliviano permanece en estado irresuelto.

\section{Otros costos económicos, sociales y políticos asociados a la mediterraneidad boliviana}

Como ya se refirió líneas atrás, los altos costos de transporte y servicios portuarios afectan negativamente la competitividad de los productos bolivianos en el comercio internacional y dificultan la expansión de su comercio exterior, que se concentra principalmente en el intercambio con los países vecinos. Bolivia tiene dificultad para proyectarse hacia la Cuenca del Pacífico, una de las cuencas de mayor desarrollo económico y comercial del mundo en las últimas décadas. La mediterraneidad limita la competitividad de la economía boliviana, incidiendo negativamente en la atracción de inversiones extranjeras y en la captación de procesos de transferencias de tecnología. En el país se ha debilitado o se ha perdido la "conciencia comercial marítima", situación que no permite planificar proyectos y negocios de desarrollo económico basados en el acceso al mar. Al carecer de una costa soberana, Bolivia no pudo entrar en contacto con las principales corrientes migratorias del siglo XIX y de principios del siglo XX, que históricamente se concentraron en los bordes de Sudamérica.

El Estado sufrió una pérdida de actividad productiva y de servicios al carecer de un territorio aledaño al mar. Estas actividades se realizaron en territorio chileno y beneficiaron a su economía. Entre otras, se podrían mencionar el transporte carretero, el transporte ferroviario, el uso de puertos, el turismo, etcétera. Los costos de transporte y servicios portua- 
rios exigidos por Chile deben pagarse en moneda dura, lo cual representa un apreciable drenaje de divisas en favor de Chile. Diversos organismos internacionales han realizado estudios que demuestran el impacto negativo que tienen los altos costos económicos que pagan los países mediterráneos. Entre ellos, se puede destacar algunos estudios del Fondo Monetario Internacional y de la UNCTAD, realizados en 1994, 2001 y 2004, que establecen que un alto porcentaje de los ingresos por concepto de exportación de los países mediterráneos están destinados al pago de servicios de transporte y seguros. Analistas internacionales como el economista Jeffrey Sachs, ${ }^{31}$ que han estudiado el impacto macroeconómico de la mediterraneidad en el crecimiento económico, estiman que los países mediterráneos pierden 0,7 puntos porcentuales en sus tasas de crecimiento, precisamente por su condición de encierro territorial. De dicho análisis, se desprende que en los últimos diez años, 1995-2004, los costos del enclaustramiento estatal ascienden a más de \$US 4,000 millones de dólares. Con esta metodología podría inferirse la significativa pérdida del producto interno bruto boliviano durante casi 130 años de desmembración marítima, desde el año 1879.

La mediterraneidad del territorio boliviano incide sin lugar a dudas en el desarrollo económico y en las condiciones sociales y políticas del país. Aunque gran parte de los impactos de la mediterraneidad son difíciles de cuantificar, ellos representan perjuicios visibles que pueden ser constatados de manera objetiva a partir de las condiciones materiales en las que se encuentra la nación y la mayoría de la población, más aún al compararlas con las de los vecinos no mediterráneos. La mediterraneidad produce obstáculos que se generan en el proceso de inserción del Estado dentro de la economía internacional, con mayor fuerza en esta etapa de globalización y regionalismo abierto; ${ }^{32}$ e inducen a que la economía na-

31 Jeffrey Sachs, es profesor de la Universidad de Harvard y director del Harvard Institute for International Development. El análisis se publicó en "The Limits of Convergent: Nature and Growth", The Economist, 1997.

32 Estudios de la Flacso en Santiago de Chile (2003), afirman que la mediterraneidad ha implicado también la imposibilidad de aprovechar los recursos marinos y del subsuelo oceánico, que deberían ser un patrimonio universal antes que un privilegio de los países con costa marítima, y de captar eficientemente los flujos migratorios de capital humano y flujos de inversión extranjera. Ella también ha fincado limitaciones significativas en el comercio exterior y una pérdida de autonomía en la administración de dicho comercio. Flacso, Estudios Económicos, Santiago, 2003. 
cional tienda a concentrarse en sí misma, perdiendo la posibilidad de desarrollar a plenitud sus ventajas competitivas potenciales, y creando al mismo tiempo una mentalidad nacional conservadora y menos abierta al mundo.

Respecto a los impactos de la mediterraneidad sobre las condiciones sociales se cuantifican comparando los Índices de Desarrollo Humano (IDH) elaborados por el PNUD, de los países sin acceso a las costas marítimas con los de sus vecinos no mediterráneos. Esta comparación permite afirmar que la población de los países mediterráneos en desarrollo ha alcanzado condiciones de vida significativamente menores que las de sus vecinos con costa. Esta evidencia no es casual, ya que se están comparando en general países con procesos históricos, características culturales, y recursos materiales relativamente similares. EI IDH es un índice que pretende captar de manera integral las dimensiones del desarrollo en el que se encuentran las poblaciones de todos los países del mundo.

Para la construcción del índice, se consideran tres grupos de variables que cubren las condiciones de salud, educación e ingreso de la población que le permite satisfacer sus necesidades básicas. Así, mientras el IDH de Bolivia en 1994 fue 0.589, el IDH promedio ponderado de los países vecinos (Brasil, Argentina, Chile y Perú) llegó a 0.798, esto es $26 \%$ mayor al del país sin litoral. Sucede lo propio cuando se compara individualmente los IDH de los países vecinos no mediterráneos con el de Bolivia. Un fenómeno similar se observa en el caso del Paraguay, el otro país sudamericano mediterráneo, y en el resto de países mediterráneos del mundo, a excepción de Suiza por ser un país desarrollado y de Mongolia, que colinda sólo con la República de China. Es indudable que los países mediterráneos en desarrollo, tienen condiciones de vida de menor calidad y un desarrollo humano menor a los de sus respectivos países limítrofes no mediterráneos, reflejando los impactos negativos de la mediterraneidad sobre el bienestar social. La diferencia de las condiciones de vida de los países africanos mediterráneos con relación a sus correspondientes vecinos con acceso al mar, a partir de los IDH menores de los primeros, es también inobjetable. ${ }^{33}$

33 Se presentan algunas cuantificaciones puntuales de los efectos de la mediterraneidad por el transporte, y la utilización de instalaciones y servicios portuarios en territorio chileno, para las operaciones de comercio exterior bolivianas; estos costos imputables a la mediterraneidad, son absorbidos básicamente por los exportadores como 
Otras implicaciones de la mediterraneidad de Bolivia se pueden resumir en una serie de situaciones no cuantificables y cuantificables como: a) Imposibilidad de utilizar y explotar los recursos marinos, dentro de las 200 millas de mar patrimonial o zona económica exclusiva (Bolivia es Estado parte de la III Convemar); b) Formación de una actitud nacional "menos abierta" al mundo, lo que repercute en un menor desempeño productivo, menos información y menores inversiones; c) Desviación de comercio en que incurren los países mediterráneos, ya que éstos tienden a concentrar su comercio exterior en los países vecinos, que no siempre ofrecen las condiciones más ventajosas comparativamente con otros mercados; $d$ ) Mayores obstáculos para aprovechar las ventajas de la globalización y la integración económica; es el caso de la dificultad real de proyectarse económicamente hacia la cuenca de pacifico asiático como una de las regiones más dinámicas en la actualidad; e) Desviación de la inversión extranjera, que tiende a asentarse en territorios con mayor acceso al "resto del mundo"; la inversión extranjera considera a la mediterraneidad como un factor limitante, dado el encarecimiento en los costos de transporte; f) Falta de contacto con las corrientes migratorias de tiempos pasados, lo que ha incidido en las limitaciones del capital humano; el flujo de emigrantes que recibieron los países vecinos no sólo amplió considerablemente sus mercados internos, sino que trajo consigo tecnología, mentalidad empresarial y laboral más eficiente, capital de inversión, contactos internacionales, entre otros. ${ }^{34}$

una suerte de impuesto que encarece el valor de sus mercancías exportables y les resta capacidad competitiva con productos similares ofrecidos en los mercados internacionales, y en el caso de las importaciones por los consumidores locales, que se ven obligados a adquirir bienes de consumo, maquinaria $\mathrm{v}$ equipos productivos $\mathrm{e}$ insumos, a precios mayores. Estos costos desglosados en costos de transporte por carretera, de transporte ferroviario, de utilización de servicios portuarios y otros adicionales ascienden a más de 30 millones de dólares por año.

34 Flacso, op. cit., nota 32, p. 76, señala que también se produce una tendencia a que la economía boliviana se concentre en sí misma y pierda, por tanto, posibilidades de desarrollar sus ventajas competitivas potenciales, y que genere distorsiones al desarrollo productivo. Además de que quede sujeta a perjuicios en el proceso de comercialización ante la implementación de barreras no arancelarias, tales como la prohibición de almacenar temporalmente minerales para exportación, como es el caso del plomo y el zinc en Antofagasta, en la actualidad. 


\section{Algunos costos cuantificables de la mediterraneidad boliviana}

Entre los costos económicos cuantificables de la mediterraneidad de Bolivia, pueden considerarse los gastos de realización de las exportaciones desde el territorio nacional hasta los puertos del Pacífico localizados en el norte chileno y de las importaciones por dichos puertos. La realización del comercio exterior comprende básicamente al transporte de las mercancías y a la utilización de los servicios portuarios. En este sentido, el costo de la mediterraneidad es el conjunto de gastos que deben efectuar los importadores y exportadores de bienes por el tránsito de su comercio por el territorio chileno, y por el uso de los servicios portuarios ofrecidos en ese país. El transporte de mercancías hacia y desde los puertos del norte de Chile se efectúa principalmente por las vías carreteras La Paz-Arica y Oruro-Pisagua, y por los ferrocarriles La Paz-Arica y Oruro-Antofagasta. Actualmente sólo se está utilizando el ferrocarril Oruro-Antofagasta, adjudicado en el tramo boliviano junto con la vía ferroviaria La Paz-Charaña, a la Empresa chilena "Cruz Blanca" S. A. mediante el proceso de capitalización de la Empresa Nacional de Ferrocarriles.

Por su parte, el valor agregado del transporte carretero, dado el monopolio que asume la Cámara Boliviana de Transporte, no puede considerarse como un gasto de mediterraneidad; este valor es erogado por operadores de comercio bolivianos y percibido por operadores de transporte bolivianos. En este sentido, el transporte por carretera hacia y desde los puertos del Pacífico implica transacciones exclusivamente entre bolivianos. Sin embargo, existen gastos que efectúan los transportistas bolivianos en territorio chileno, tales como mantenimiento de sus vehículos, peajes, compra de combustible, estadía y viáticos de permanencia, entre otros. En lo que concierne a los gastos por el transporte ferroviario del comercio exterior de Bolivia que se erogan en territorio chileno son también costos imputables a la mediterraneidad. Así, los operadores de comercio bolivianos que utilizan el transporte ferroviario erogan anualmente a la empresa de ferrocarriles en Chile, un monto aproximado de 5,2 millones de dólares. Otro gasto incurrido por parte de los operadores de comercio corresponde a la utilización de servicios portuarios, por manipuleo, almacenamiento, estiba o desestiba, entre otros, de las mercancías importadas o exportadas. La utilización de los servi- 
cios portuarios en Antofagasta, Arica e Iquique genera un costo para el comercio exterior boliviano que es percibido por la economía chilena. El valor del comercio de Bolivia en estos puertos de Chile llegó en 2004 a casi 1500 millones de dólares, algo más de la mitad del valor total del comercio exterior del país en ese año. Así, el costo total por servicios portuarios alcanza aproximadamente 16 millones de dólares que se transfieren a Chile. ${ }^{35}$

\section{EL DIFERENDO POR LA MEDITERRANEIDAD DE BOLIVIA EN EL MARCO DE LA CONVENCIÓN DE LAS NACIONES UNIDAS SOBRE DERECHO DEL MAR}

Conforme al derecho internacional marítimo, uno de los referentes fundamentales y base para la implementación de mecanismos de solución del diferendo Bolivia-Chile-Perú, lo constituye sin lugar a dudas la Convención de las Naciones Unidas sobre el Derecho del Mar (Convención del Mar, también llamada Convemar), la cual es considerada uno de los tratados multilaterales más importantes de la historia, desde la aprobación de la Carta de las Naciones Unidas. Su relevancia jurídica es tal que ha sido llamada "la Constitución de los Océanos". ${ }^{36}$ Consta de un preámbulo, 17 partes y nueve anexos. Para los efectos del caso que nos ocupa es muy importante la parte X de la convención denominada "Derecho de acceso al mar y desde el mar de los Estados sin litoral y libertad de tránsito". Ésta consta de nueve artículos, que van del 124 al 132, y tocan con cierto detalle los puntos centrales que caracterizan la condición de mediterraneidad.

Ahora bien, antes de pasar a una breve descripción del contenido de los mismos, conviene advertir que la Convemar ya fue ratificada por los dos principales protagonistas del diferendo: Bolivia depositó los instrumentos de ratificación el 28 de abril de 1995, y Chile hizo lo propio el 25 de agosto de 1997. Llama la atención el caso del Perú que, no obstante

35 Unidad de política económica, La Paz, Ministerio de Hacienda, mayo de 2005.

36 La Convemar fue aprobada, tras 9 años de trabajo, el 30 de abril de 1982 en Nueva York, Estados Unidos de América y abierta a su firma por parte de los Estados, el 10 de diciembre de 1982, en Montego Bay, Jamaica, en la 182a. sesión plenaria de la III Conferencia de las Naciones Unidas sobre el Derecho del Mar. Entró en vigor el 16 de noviembre de 1994, un año después de la 60a. ratificación (realizada por Guyana). 
fue uno de los principales promotores de la II y III conferencias del mar, y en particular de la tesis del mar jurisdiccional o de la zona económica exclusiva una vez que fue aprobada, hasta el momento no se ha vinculado a la convención. ${ }^{37}$ Igualmente, si bien en los últimos años Bolivia, Chile y Perú han realizado algunos esfuerzos negociadores y acciones directas pero insuficientes para resolver la controversia, al hacerlo los gobiernos no han invocado expresamente el contenido de la parte $\mathrm{X}$ de la convención, aunque se observen ciertas analogías y coincidencias entre dichas acciones gubernamentales y estos preceptos vinculantes.

El artículo 124 (Términos empleados) estipula que para los efectos de la convención se entiende por a) "Estado sin litoral" un Estado que no tiene costa marítima; b) "Estado de tránsito" un Estado con o sin costa marítima, situado entre un Estado sin litoral y el mar, a través de cuyo territorio pase el tráfico en tránsito; c) "Tráfico en tránsito" el tránsito de personas, equipaje, mercancías y medios de transporte a través del territorio de uno o varios Estados de tránsito, cuando el paso a través de dicho territorio, con o sin trasbordo, almacenamiento, ruptura de carga o cambio de modo de transporte, sea sólo una parte de un viaje completo que empiece o termine dentro del territorio del Estado sin litoral; $d$ ) "Medios de transporte": 1) El material rodante ferroviario, las embarcaciones marítimas, lacustres y fluviales y los vehículos de carretera; 2) Los porteadores y los animales de carga, cuando las condiciones locales requieran su uso. La disposición termina expresando que los Estados sin litoral y los Estados de tránsito podrán, por mutuo acuerdo, incluir como medios de transporte las tuberías y gasoductos y otros medios de transporte distintos de los antes señalados.

El artículo 125 (Derecho del mar y desde el mar y libertad de tránsito) dice que los Estados sin litoral tendrán el derecho de acceso al mar y desde el mar para ejercer los derechos que se estipulan en la convención, incluidos los relacionados con la libertad de la alta mar y con el patrimonio común de la humanidad; que para tal fin gozarán también de libertad de tránsito a través del territorio de los Estados de tránsito por todos los medios de transporte. Que las condiciones y modalidades para el ejercicio de la libertad de tránsito serán convenidas entre los Estados sin litoral

37 Otros Estados del Cono Sur, que ya ratificaron la Convemar, son Paraguay (país mediterráneo), 26 de septiembre de 1986; Brasil, el 22 de diciembre de 1988; Uruguay, el 10 de diciembre de 1992; y Argentina, el 1o. de diciembre de 1995. 
y los Estados de tránsito interesados mediante acuerdos bilaterales, subregionales o regionales. Finalmente, que los Estados de tránsito, en el ejercicio de su plena soberanía sobre su territorio, tendrán derecho a tomar todas las medidas necesarias para asegurar que los derechos y facilidades estipulados en esta parte para los Estados sin litoral no lesionen en forma alguna sus intereses legítimos.

El artículo 126 (Exclusión de la aplicación de la cláusula de la nación más favorecida) es claro al indicar que las disposiciones de la convención, así como los acuerdos especiales relativos al ejercicio del derecho de acceso al mar y desde el mar, que establezcan derechos y concedan facilidades por razón de la situación geográfica especial de los Estados sin litoral, quedan excluidos de la aplicación de la cláusula de la nación más favorecida.

El artículo 127 (Derechos de aduana, impuestos u otros gravámenes) marca dos señalamientos, el primero en cuanto al tráfico en tránsito que no estará sujeto a derechos de aduana, impuestos u otros gravámenes, con excepción de las tasas impuestas por servicios específicos prestados en relación con dicho tráfico; el segundo acerca de los medios de transporte en tránsito y otros servicios proporcionados a los Estados sin litoral y utilizados por ellos, los cuales no estarán sujetos a impuestos o gravámenes más elevados que los fijados para el uso de los medios de transporte del Estado de tránsito.

El artículo 128 (Zonas francas y otras facilidades aduaneras) es concreto al establecer que para facilitar el tráfico en tránsito, podrán establecerse zonas francas $u$ otras facilidades aduaneras en los puertos de entrada y de salida de los Estados de tránsito, mediante acuerdo entre estos Estados y los Estados sin litoral.

Ell artículo 129 (Cooperación en la construcción y mejoramiento de los medios de transporte) manifiesta que cuando en los Estados de tránsito no existan medios de transporte para dar efecto a la libertad de tránsito o cuando los medios existentes, incluidas las instalaciones y equipos portuarios, sean deficientes en cualquier aspecto, los Estados de tránsito y los Estados sin litoral interesados podrán cooperar en su construcción o mejoramiento.

De manera complementaria, el artículo 130 (Medidas para evitar o eliminar retrasos u otras dificultades de carácter técnico en el tráfico en tránsito) refiere que los Estados de tránsito adoptarán todas las medidas apropiadas para evitar retrasos u otras dificultades de carácter técnico en 
el tráfico en tránsito; y en caso de que se produzcan tales retrasos o dificultades, las autoridades competentes de los Estados de tránsito y de los Estados sin litoral interesados cooperarán para ponerles fin con prontitud.

El artículo 131 (Igualdad de trato en los puertos marítimos), preceptúa que los buques que enarbolan el pabellón de Estados sin litoral gozarán en los puertos marítimos del mismo trato que el concedido a otros buques extranjeros.

Para terminar, el artículo 132 (Concesión de mayores facilidades de tránsito) acota que la convención no entraña de ninguna manera la suspensión de las facilidades de tránsito que sean mayores que las previstas en la misma y que hayan sido acordadas entre los Estados partes en ella o concedidas por un Estado parte; asimismo que la convención tampoco impedirá la concesión de mayores facilidades en el futuro.

Como se puede apreciar, la parte $\mathrm{X}$ de la Convemar es bastante explícita en cuanto a los derechos, obligaciones y opciones reales de cooperación que disponen los Estados sin litoral para acceder a los beneficios de los recursos marinos y oceánicos orientándolos a su desenvolvimiento económico, político y social, y que han sido sintetizados por la comunidad internacional — después de tres décadas de discusión multilateralcomo el núcleo duro de prerrogativas de acceso al mar y desde el mar, y libertad de tránsito de todos los Estados mediterráneos del mundo, sin distingo entre pueblos en desarrollo y desarrollados. En este sentido, y considerando que tanto Bolivia como Chile son signatarios de pleno derecho de la convención, amén que están vinculados a ella al utilizar antes y después de su ratificación, en la ley y en la práctica marítimas, los amplios recursos jurídicos que la Convemar ofrece a lo largo de sus 11 capítulos, 17 partes y nueve anexos, no parece haber más impedimento que la falta de voluntad política o la convalidación tácita de la tesis que sostiene que "lo ganado en una guerra sólo se pierde con otra guerra", para arribar a un arreglo definitivo y ejemplar de una controversia que, ante todo, pone en tela de juicio el tan mentado y cuestionable espíritu de solidaridad latinoamericana. Es decir, de no lograr las partes en conflicto la construcción de una solución final, justa y equitativa para todos, apegada a derecho y mirando de frente al futuro, el fracaso continuará junto con el resentimiento y la frustración y quedará reafirmado lo que hasta ahora ha sido evidente, esto es, que tratándose de territorios y posesiones territoriales los Estados, aun vecinos y hermanos por la herencia histórica y el 
pasado colonial, no están dispuestos a ceder un solo centímetro de territorio, aunque éste haya sido obtenido a través de una guerra de agresión.

\section{A MANERA DE REFLEXIÓN FINAL}

Si bien el enclaustramiento impuesto a Bolivia es en esencia un asunto bilateral, no le compete exclusivamente a Chile y a Bolivia, sino al equilibrio y al proceso de integración de la región. Hay una vocación histórica común entre el sur del Perú, el norte de Chile y el oeste de Bolivia cuya economía, lengua y cultura son comunes como es común el futuro a construir. Será difícil tener un proceso de integración completo desde el Atlántico hasta el Pacífico, considerando a Brasil, Argentina, Paraguay y Perú, si Bolivia y Chile no resuelven definitivamente el tema de la soberanía, porque los corredores biocéanicos que pasan por territorio boliviano, que deben unir una punta y la otra de los dos océanos, lo harán de manera fluida, clara, útil y, sobre todo, positiva para la región cuando se haya resuelto este problema que, entre tanto, continuará entorpeciendo un proceso de integración históricamente ineluctable.

A lo largo de la presente investigación se han plasmado innumerables apreciaciones, criterios, conceptos y consideraciones terminales producto del análisis crítico del objeto de estudio que es el diferendo Bolivia-Chile-Perú por la soberanía territorial y la búsqueda de una salida al Océano Pacífico. La controversia ha sido uno de los detonantes de la inestabilidad tanto de Bolivia, como de Perú ya que ambos Estados, al perder soberanía y territorio en la Guerra del Pacífico padecieron consecuencias como una gran inestabilidad política, económica y social, lo que ocasionó vulnerabilidad y, por ende, pérdida del prestigio internacional.

Bolivia podría tener acceso directo al mar (y por varias rutas) confederándose con Perú, Chile, Argentina o Brasil. Una unión económica y política de la región ayudaría a potenciar a todos sus componentes, disminuiría las tensiones fronterizas y permitiría que las etnias y regiones marginadas tengan mayores libertades. Aimaras, quéchuas, guaraníes o jíbaros divididos por fronteras artificiales tendrían la posibilidad de entrelazarse mejor y así lograr una pluralidad que, al ser tolerada, pueda unirse y alcanzar un desarrollo para toda América Latina. Además, este problema refleja la falta de unión y cooperación entre los países latinoamericanos, que además de ser negativa, perjudica para un proyecto alternativo de alianzas en el campo económico primordialmente. 
Si los países que se encuentran en la misma situación de crisis, decidieran crear un organismo que se ocupara específicamente del estudio de la situación de cada uno de los miembros referente a la pobreza, dependencia, límites fronterizos, recursos naturales, etcétera, tal vez en el plano de las relaciones internacionales se podrían ver resultados positivos dirigidos a una eficiente integración latinoamericana.

Debe hacerse una revisión cuidadosa de los tratados y acuerdos que se han firmado al respecto, y verificar a la luz de su actualización si aún pueden ser aplicados en la actualidad, o bien, denunciados o adecuados con base en el principio rebus sic stantibus o en la costumbre internacional. Así, una alternativa viable sería elaborar un nuevo tratado bilateral o multilateral que tenga como base los intereses de los tres países, sin inclinarse hacia ninguno de ellos, aunque es de reconocer que va a ser muy difícil, puesto que Chile no va a acceder a devolver el territorio que arrebató a Bolivia en la conflagración de 1879-1883.

Al reconocer que se trata de un conflicto geopolítico, es conveniente hacer un análisis de los estudios que se han elaborado dentro de cada país en la actualidad para que éstos hagan propuestas en foros internacionales o entre los países en conflicto. Perú y Bolivia podrían unirse en un proceso de integración, porque solamente así se puede romper el desequilibrio de la relación con Chile que es un país económicamente más desarrollado y políticamente más estable que Perú y Bolivia.

\section{BIBLIOGRAFÍA}

Alperovich y Sliezkin, Historia de América Latina, México, Ediciones Quinto Sol, 1983.

BeCerra Ramírez, Manuel, Derecho internacional público, México, McGraw-Hill, 1999.

Bethell, Leslie (ed.), Historia de América Latina, t. 6: América Latina independiente 1820-1870, Barcelona, Crítica, 2000.

CaIVAno, Tomás, La guerra de América entre Perú, Chile y Bolivia, Lima, Científica, 1979.

Comisión Andina de Juristas, Impunidad y derecho penal internacional. Un estudio empírico dogmático sobre Colombia, Bolivia, Perú, Chile y Argentina, CAJ Ediciones, 1997.

Cueva, Agustín, El desarrollo del capitalismo en América Latina, México, Siglo XXI, 1988. 
FigueroA Pla, Uldaricio, La demanda maritima boliviana en los foros internacionales, Andrés Bello, 1992.

Gobierno de la República de Bolivia, El libro azul. El problema marítimo boliviano, La Paz, 2004.

HEINE, Jorge, Anuario de Políticas Exteriores Latinoamericanas 1990-1991, México, Editora Nueva Sociedad Prospel, 1993.

JACQUES, Lamert, América Latina: estructuras sociales e instituciones politicas, 3a. ed., México, Editorial Ariel, 1978.

Kaplan, Marcos, Aspectos del Estado en América Latina, 5a. ed., México, UNAM, IIJ-IIE, 1985.

LÓPEZ, Jacinto, Historia de la guerra del guano y el salitre o Guerra del Pacífico entre Chile, Bolivia y el Perú, Lima, Milla Batres, 1979.

ONU, La Tercera Convención de las Naciones Unidas sobre el Derecho del Mar, Nueva York, Publicaciones oficiales, 1985.

OSMANZCYCK, Edmund, Enciclopedia mundial de las relaciones internacionales y naciones unidas, México, FCE, 1980.

Pelayo, Mauricio, La Guerra del Pacifico, Monografías, 2001.

PEÑA, Orlando, Estados y territorios en América Latina y el Caribe, México, Ediciones Era, 1989.

SELSER, Gregorio, Cronología de las intervenciones extranjeras en América Latina, t. II: 1849-1898, México, 1995, colección Cuadernos del CEIICH, serie Fuentes.

TOMASSINI, Luciano, Las relaciones internacionales de América Latina, México, Siglo XXI, 1981.

VelÁzQUez ElizARRARÁs, Juan Carlos, El derecho internacional público frente al proceso globalizador, México, UNAM-Universidad de Texas, DEP-Filosofía, 1998.

_- El derecho internacional público en la agenda política de las relaciones internacionales, México, UNAM, FCPS-DGAPA, 2005.

—_ Nuevos desarrollos temáticos para el estudio del derecho internacional público, México, UNAM, FCPS-DGAPA, 2004. 
FigueroA Pla, Uldaricio, La demanda maritima boliviana en los foros internacionales, Andrés Bello, 1992.

Gobierno de la República de Bolivia, El libro azul. El problema marítimo boliviano, La Paz, 2004.

HEINE, Jorge, Anuario de Políticas Exteriores Latinoamericanas 1990-1991, México, Editora Nueva Sociedad Prospel, 1993.

JACQUES, Lamert, América Latina: estructuras sociales e instituciones politicas, 3a. ed., México, Editorial Ariel, 1978.

Kaplan, Marcos, Aspectos del Estado en América Latina, 5a. ed., México, UNAM, IIJ-IIE, 1985.

LÓPEZ, Jacinto, Historia de la guerra del guano y el salitre o Guerra del Pacífico entre Chile, Bolivia y el Perú, Lima, Milla Batres, 1979.

ONU, La Tercera Convención de las Naciones Unidas sobre el Derecho del Mar, Nueva York, Publicaciones oficiales, 1985.

OSMANZCYCK, Edmund, Enciclopedia mundial de las relaciones internacionales y naciones unidas, México, FCE, 1980.

Pelayo, Mauricio, La Guerra del Pacifico, Monografías, 2001.

PEÑA, Orlando, Estados y territorios en América Latina y el Caribe, México, Ediciones Era, 1989.

SELSER, Gregorio, Cronología de las intervenciones extranjeras en América Latina, t. II: 1849-1898, México, 1995, colección Cuadernos del CEIICH, serie Fuentes.

TOMASSINI, Luciano, Las relaciones internacionales de América Latina, México, Siglo XXI, 1981.

VelÁzQUez ElizARRARÁs, Juan Carlos, El derecho internacional público frente al proceso globalizador, México, UNAM-Universidad de Texas, DEP-Filosofía, 1998.

_- El derecho internacional público en la agenda política de las relaciones internacionales, México, UNAM, FCPS-DGAPA, 2005.

—_ Nuevos desarrollos temáticos para el estudio del derecho internacional público, México, UNAM, FCPS-DGAPA, 2004. 